\title{
Effect of secondary organic aerosol coating thickness on the real-time detection and characterization of biomass-burning soot by two particle mass spectrometers
}

\author{
Adam T. Ahern ${ }^{1}$, Ramachandran Subramanian ${ }^{1}$, Georges Saliba ${ }^{1}$, Eric M. Lipsky ${ }^{1,2}$, Neil M. Donahue ${ }^{1}$, and \\ Ryan C. Sullivan ${ }^{1}$ \\ ${ }^{1}$ Center for Atmospheric Particle Studies, Carnegie Mellon University, Pittsburgh, PA, 15213, USA \\ ${ }^{2}$ Penn State Greater Allegheny, 4000 University Drive, McKeesport, Pennsylvania 15132, USA
}

Correspondence to: Ryan C. Sullivan (rsullivan@cmu.edu)

Received: 10 June 2016 - Published in Atmos. Meas. Tech. Discuss.: 15 July 2016

Revised: 31 October 2016 - Accepted: 18 November 2016 - Published: 22 December 2016

\begin{abstract}
Biomass burning is a large source of lightabsorbing refractory black carbon (rBC) particles with a wide range of morphologies and sizes. The net radiative forcing from these particles is strongly dependent on the amount and composition of non-light-absorbing material internally mixed with the rBC and on the morphology of the mixed particles. Understanding how the mixing state and morphology of biomass-burning aerosol evolves in the atmosphere is critical for constraining the influence of these particles on radiative forcing and climate. We investigated the response of two commercial laser-based particle mass spectrometers, the vacuum ultraviolet (VUV) ablation LAAPTOF and the IR vaporization SP-AMS, to monodisperse biomass-burning particles as we sequentially coated the particles with secondary organic aerosol (SOA) from $\alpha$-pinene ozonolysis. We studied three mobility-selected soot core sizes, each with a number of successively thicker coatings of SOA applied. Using IR laser vaporization, the SP-AMS had different changes in sensitivity to $\mathrm{rBC}$ compared to potassium as a function of applied SOA coatings. We show that this is due to different effective beam widths for the IR laser vaporization region of potassium versus black carbon. The SP-AMS's sensitivity to black carbon (BC) mass was not observed to plateau following successive SOA coatings, despite achieving high OA : BC mass ratios greater than 9 . We also measured the ion fragmentation pattern of biomass-burning $\mathrm{rBC}$ and found it changed only slightly with increasing SOA mass. The average organic matter ion signal measured by the LAAPTOF demonstrated a positive correlation with the condensed SOA mass on in-
\end{abstract}

dividual particles, despite the inhomogeneity of the particle core compositions. This demonstrates that the LAAPTOF can obtain quantitative mass measurements of aged sootparticle composition from realistic biomass-burning particles with complex morphologies and composition.

\section{Introduction}

Particles containing black carbon (BC) are largely anthropogenic and have the third largest warming effect on the planet, after $\mathrm{CO}_{2}$ and methane (Bond et al., 2013; Ramanathan and Carmichael, 2008). This makes BC-containing particles a likely target for climate change mitigation policy (Anenberg et al., 2012). However, there is high uncertainty regarding the climate forcing of $\mathrm{BC}$, and thus any potential benefits from BC control technologies and policies (Jacobson, 2001). The uncertainty stems from the variable optical, chemical, and physical properties of BC, which affect particle radiative properties and lifetime, respectively. The properties of BC-containing particles can change as atmospheric oxidants react with gas-phase vapors; the products of these reactions can condense onto the light-absorbing aerosol. Although this condensed material may not absorb light itself, it can affect the lifetime and cloud-nucleation ability of the $\mathrm{BC}$-containing particle and increase the internally mixed BC absorption of sunlight by as much as a factor of 2 (Bond et al., 2013; Chung and Seinfeld, 2002; Jacobson, 2001; Lack et 
al., 2009; Moffet et al., 2008; Ramanathan and Carmichael, 2008).

The burning of non-fossil-fuel biomass, either as biofuel, agricultural refuse, or in wildfires, is the largest source of light-absorbing BC-containing particles globally. However, the effect of aging on the biomass-burning aerosol (BBA) is not well characterized (Bond et al., 2013). In some cases, coemitted organic gases become oxidized and condense on the BBA, simultaneously reducing BBA atmospheric lifetime and increasing BBA light absorptivity (Lack et al., 2009; Mikhailov et al., 2006; Yokelson et al., 2009). In other smoke plumes, there has been no observed increase in organic matter (OM) with aging, and in a few cases a decrease in OM has been reported, likely due to dilution-induced evaporation (Cubison et al., 2011; May et al., 2013). In order to identify the contribution of various chemical processes to the compositional changes in BC-containing particles, measurements of particle composition must be carried out with a temporal resolution similar to or faster than the timescale of the chemical processes. Improved mass measurements of $\mathrm{BC}$ and internally mixed material will enable more accurate model simulations that constrain the climate forcing by black carbon and other aerosol components.

Particle mass spectrometers provide information about the chemical composition of atmospheric aerosols with a time resolution comparable to their transformation processes. In this paper we investigate the response of two commercial laser-based particle mass spectrometers to the systematic condensation of secondary organic aerosol (SOA) onto complex biomass-burning soot particles. One instrument is an infrared (IR) laser vaporization soot-particle aerosol mass spectrometer (SP-AMS, Aerodyne Research Inc.), while the other is a laser desorption-ionization single-particle mass spectrometer (LDI-SP-MS) known as the laser ablation aerosol particle time of flight mass spectrometer (LAAPTOF, AeroMegt $\mathrm{GmbH}$ ). Both instruments provide compositional information regarding the core composition of BBA particles as well as secondary condensed components on a timescale of $10 \mathrm{~min}$ or less. However, each has quantitative challenges related to particle mixing state and morphology that are the subject of ongoing research (Corbin et al., 2014; Onasch et al., 2015; Spencer and Prather, 2006; Willis et al., 2014). Herein we evaluate the ability of the two instruments to measure the composition of BBA composed of both a BC core and SOA coating, as we simulate atmospheric aging by coating primary BBA particles with complex secondary organic material in a chamber reactor.

We confirm that significant SOA coatings on BC cause only small changes in the ion fragmentation patterns of elemental carbon (EC) in the SP-AMS. EC is defined as ions detected by mass spectrometry that consist of only carbon atoms. We show that the infrared laser beam in the SP-AMS has a different effective beam width and therefore different detection efficiency for alkali metals versus BC. The feasibility of quantitative measurements of OM by the LAAPTOF in complex and realistic particles containing inorganic salts, refractory black carbon ( $\mathrm{rBC}$ ), and SOA was also investigated. We demonstrate that there is a positive correlation between the LAAPTOF-measured OM ion signal and the SOA mass condensed on BBA particles. This is significant given the especially complex composition of BBA and is highly encouraging for achieving mass quantitative single-particle measurements of other complex ambient particle matrices. In this work, we will use the term "SOA" to describe the condensed-phase organic material that was formed from $\alpha$ pinene ozonolysis. We will use "OM" to discuss all condensed organic matter, including mass that is primary or secondary in nature. Organic ions measured by mass spectrometry will be identified as OM because in this work we cannot strictly differentiate between primary and secondary organic material.

\subsection{Characterization of carbonaceous aerosol by SP-AMS}

The SP-AMS is a variant of the conventional aerosol mass spectrometer that includes an intracavity IR laser that can vaporize light-absorbing refractory material. A conventional AMS includes a $600{ }^{\circ} \mathrm{C}$ heater to vaporize aerosol particles in a vacuum before ionization (Decarlo et al., 2006; Jayne et al., 2000). Two species of interest are difficult and impossible to detect, respectively, with a conventional AMS: potassium and $\mathrm{rBC}$. Refractory is an operationally defined term describing any material not readily vaporized, such as by the $600{ }^{\circ} \mathrm{C}$ heater in a conventional AMS. Potassium and $\mathrm{rBC}$ are chemical species that are used as inert, nonvolatile tracers for biomass burning (Andreae, 1983; Hennigan et al., 2011; Lee et al., 2016). The sensitivity of the SP-AMS to rBC has been shown to increase with the addition of organic coatings to rBC-containing particles. Willis et al. (2014) showed that the increased sensitivity was due to increased overlap between the particle beam and the IR beam that vaporizes the particles. The particles become more tightly focused by the aerodynamic lens inlet with increasing coating thickness and thus sphericity, causing a larger portion of the particle beam to intersect with the IR laser beam. The fraction of rBCcontaining particles that are vaporized by the IR laser is defined by Onasch et al. (2012) as the shape-dependent collection efficiency, $E_{\mathrm{IR}}$, and is the determining factor for the sensitivity of the SP-AMS to rBC. Willis et al. (2014) measured the $E_{\mathrm{IR}}$ for $\mathrm{rBC}$ using a beam-width probe with a $\mathrm{rBC}$ aerosol calibration standard (Regal Black, Cabot) coated to varying degrees with dioctyl sebacate (DOS), a surrogate for primary or hydrocarbon-like OM. They observed that the $E_{\mathrm{IR}}$ was less than unity for uncoated, collapsed $\mathrm{rBC}$ particles such as Regal Black but, for urban ambient particles and DOS-coated Regal Black, $E_{\mathrm{IR}}$ was close to unity. However, real-world BBA has a different composition than Regal Black, with particles that are less spherical and that contain inorganic salts (e.g., potassium chloride) that may be internally or exter- 
nally mixed with rBC (Huffman et al., 2005; Li et al., 2003; Onasch et al., 2012). We will show that as BBA is coated with $\mathrm{OM}$, the SP-AMS ion signal response to the mass of potassium and $\mathrm{rBC}$ increases. Furthermore, we will show that the SP-AMS response to potassium increases more rapidly than that for $\mathrm{rBC}$ for equivalent amounts of OM coating, despite the species being internally mixed. We believe that this is in part due to the ability of components with low ionization energy to be ionized directly upon vaporization (Carbone et al., 2015; Drewnick et al., 2006). However, most chemical components in the SP-AMS undergo sequential vaporization followed by $70 \mathrm{eV}$ electron ionization of the neutral vapors. This allows for extensive but reproducible molecular fragmentation and subsequent classification and detection of the resulting ions in the high-resolution time-of-flight mass spectrometer. The IR laser vaporization enables the subsequent ionization and thus detection of refractory material in particles containing $\mathrm{rBC}$ that strongly absorbs the IR laser energy. The vapors produced by the IR laser are ionized by the same electron source used when vaporization is performed only with the $600^{\circ} \mathrm{C}$ heater. The reproducibility of the ion fragmentation by electron ionization has led researchers to investigate the possibility of using the ratios of the various detected EC fragments $\left(\mathrm{C}_{x}^{+}\right)$to perform source apportionment of rBC. Corbin et al. (2014) showed that fullerene-rich particles produced a higher ratio of $\mathrm{C}_{4}^{+}$to $\mathrm{C}_{3}^{+}$than particles from higher temperature combustion did, which did not contain substantial fullerenes. Onasch et al. (2015) confirmed that fragmentation of larger graphitic molecules was a minor source of $\mathrm{C}_{4}^{+}$cations in addition to the direct ionization of vaporized $\mathrm{rBC}$. This suggests that the $\mathrm{EC}$ fragmentation pattern could be used to differentiate between $\mathrm{rBC}$ generated from different types of combustion (e.g., diesel vs. biomass combustion). Here we investigate the effect of atmospheric aging in the form of OM coatings on these $\mathrm{EC}$ ion ratios.

\subsection{Characterization of carbonaceous aerosol by LDI-SP-MS}

The LAAPTOF is an LDI-SP-MS using a VUV excimer laser pulse to ablate and ionize individual particles simultaneously. This enables the analysis of a wider range of particle compositions and types than is possible with the AMS, even when the IR laser is used. High-time-resolution measurements of individual particles are achieved; an aerodynamic size and bipolar mass spectrum can be obtained for each particle. LDI-SP-MS also provides much greater mass sensitivity compared to the less efficient electron ionization scheme because the laser ionization produces many more ions than electron ionization per mole of analyte (Farmer and Jimenez, 2010; Murphy, 2007; Pratt and Prather, 2012; Sullivan and Prather, 2005). However, the large number of ions produced per particle can result in poor MS resolution and/or ion plume chemistry after desorption-ionization. The molecular fragmentation is also less reproducible compared to $70 \mathrm{eV}$ elec- tron ionization due to laser shot-to-shot variability, inhomogeneity of the laser pulse, and varying optical properties of individual particles. Generation of ions directly from each particle introduces important matrix effects where the particle's composition and properties strongly dictate its interaction with the VUV laser pulse, the distribution of laser energy to the particle's constituents, and the resulting ion signal and fragmentation (Gross et al., 2000; Mansoori et al., 1996; Reinard and Johnston, 2008; Steele et al., 2005; Thomson et al., 1997; Wenzel and Prather, 2004).

Despite these challenges, LDI-SP-MS can obtain quantitative measurements of individual particle composition and its evolution. Effective demonstrations of data analysis strategies for achieving quantitative LDI-SP-MS measurements include restricting the analysis to particles of a similar particle type based on their mass spectrum, normalization of ion peak areas to total ion signal, the use of ion peak area ratios, sensitivity calibration by comparison to co-located speciated mass measurements, and signal averaging over numerous individual measurements (Bhave et al., 2002; Fergenson et al., 2001; Gross et al., 2000; Healy et al., 2013; Jeong et al., 2011; Pratt and Prather, 2012; Spencer and Prather, 2006; Sullivan et al., 2009; Sullivan and Prather, 2005). Although the ion plume chemistry can complicate analysis, the species known to cause ion plume effects (e.g., water, inorganic salts) are generally present in the mass spectra and can thereby inform the analysis (Murphy, 2007; Murray and Russell, 1994; Neubauer et al., 1998). In this study, we account for laser shot-to-shot inconsistencies by averaging over particles of similar size and composition.

Spencer and Prather (2006) used graphite spark-generated EC with condensed unleaded fuel to calibrate the ATOFMS LDI-SP-MS and found a linear relationship between the ratio of summed select OM cation signals to summed select EC cation signals, as the mass of OM condensed on the EC was increased. However, as pointed out by Gysel et al. (2012), EC from graphite spark discharge has different optical properties than combustion soot. Before such analysis can be used with confidence on realistic combustion BBA and complex SOA, two key differences between soot and BBA must be addressed, namely the variable morphology of BBA and the presence of inorganic salts. Inorganic salts, such as the potassium chloride observed in BBA, are very readily ionized ( $\mathrm{Li}$ et al., 2003; Reid et al., 2005; Zauscher et al., 2013). They therefore can generate a dense ion cloud that may reduce MS resolution and can interfere with the formation/detection of other ions (Murphy, 2007). The presence of potassium, and the irregular shape and strongly light-absorbing nature of BBA, presents an especially complex matrix for LDI-SP-MS. We evaluated the ability of the LAAPTOF with its $193 \mathrm{~nm}$ laser to generate and detect $\mathrm{OM}$ ion signal proportional to the mass of realistic SOA condensed on a BBA particle. 


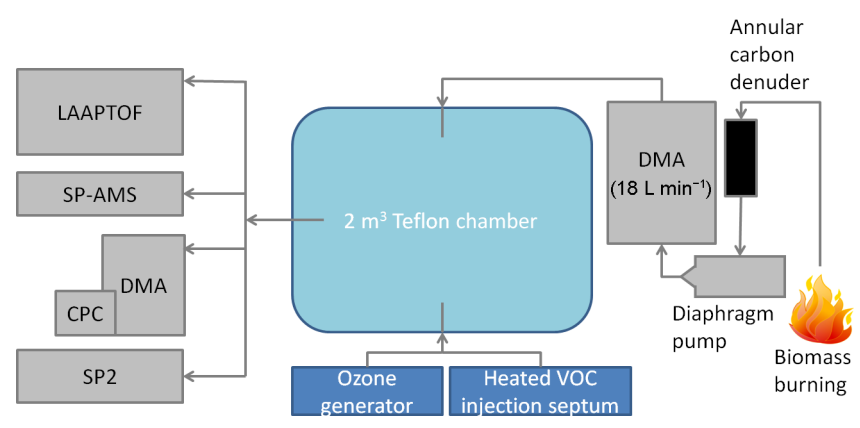

Figure 1. Experimental setup including size-selected biomassburning aerosol generation, environmental aging chamber for sequential coating with $\alpha$-pinene SOA, and subsequent online characterization with particle instrumentation.

\section{Experimental methods}

\subsection{Experimental particle generation and conditioning}

In Fig. 1 we display the experimental setup for the generation, coating, and characterization of monodisperse BBA particles. For these experiments, we burned European white birch bark in a cookstove and sampled the smoke from the flaming phase $1 \mathrm{~m}$ above the fire through $1 / 2$ in. o.d. stainless-steel tubing. We removed the gas-phase organics from the smoke by pulling polydisperse smoke through a $20^{\circ} \mathrm{C}$ annular activated-carbon denuder with a diaphragm pump. The same pump then pushed the denuded aerosol sample through a series of ${ }^{85} \mathrm{Kr}$ neutralizers and a differential mobility analyzer (DMA; TSI, model 3081) with a sample flow of $4.0 \mathrm{~L} \mathrm{~min}^{-1}$ and a non-circulating sheath flow of $18 \mathrm{~L} \mathrm{~min}^{-1}$ to select a narrow range of mobility particle diameters. We then injected the monodisperse soot particles into a $2 \mathrm{~m}^{3}$ Teflon chamber at a rate of $4.0 \mathrm{~L} \mathrm{~min}^{-1}$ until the concentration was between 2000 and 14000 particles $\mathrm{cm}^{-3}$. This typically took less than $30 \mathrm{~min}$. During this time, we continuously fueled the fire to maintain flaming conditions. Before soot injection, we partially filled the chamber with clean filtered dry air. Although the diaphragm pump generated some small particles (with mobility diameters less than $50 \mathrm{~nm}$ ), they were smaller than the selected soot particles (143 to $220 \mathrm{~nm}$ mobility diameter) and thus not transmitted through the DMA into the chamber.

We characterized the nascent soot particles with a suite of particle instruments described below and confirmed that the particles were nearly monodisperse; doubly charged particles were always less than $10 \%$ by number. We then injected precursor gases for SOA formation. We generated ozone by flowing oxygen through a corona-discharge ozone generator (Azco, HTU500AC) until the chamber concentration reached $\sim 300$ ppb. We measured the ozone concentration with a UV photometric ozone monitor (Dasibi, 1008-PC). We injected 0.1 or $0.2 \mu \mathrm{L}$ aliquots of $\alpha$-pinene (Sigma Aldrich, >99\%) through an airtight heated septum flushed with clean air. We used serial injections of $\alpha$-pinene to generate successively thicker SOA coatings on the soot cores. Chamber experiments with several steps of SOA production typically lasted 3-4 h, stopping after homogenous nucleation prevented additional coating of soot seeds.

\subsection{Particle component mass measurements}

We characterized the soot and the SOA coatings using a number of different methods. We used three instruments to measure the rBC: a Droplet Measurement Technologies single-particle soot photometer (SP2) (Schwarz et al., 2010; Stephens et al., 2003), the LAAPTOF mass spectrometer, and an Aerodyne SP-AMS (Onasch et al., 2012). Extensive descriptions of the SP2 and SP-AMS instruments are available elsewhere and thus we provide only a brief overview. For the LAAPTOF we describe the salient features below; a more detailed discussion of the LDI-SP-MS technique is available in the form of a review article by Murphy (2007) and literature descriptions of other closely related instruments (Marsden et al., 2016; Pratt et al., 2009; Sullivan and Prather, 2005; Thomson et al., 2000; Zelenyuk et al., 2009).

The LAAPTOF is a commercially available singleparticle mass spectrometer (AeroMegt $\mathrm{GmbH}$ ) that uses laser desorption-ionization to generate positive and negative ions from individual particles that are subsequently detected by a bipolar time-of-flight mass spectrometer (TOFWerk, AG) (Gemayel et al., 2016; Marsden et al., 2016). The particles are focused into the ionization region by an aerodynamic lens. Normally the particle time of flight is measured by light scattering between two $405 \mathrm{~nm}$ continuous-wave lasers (OBIS, Coherent Inc.) to determine the velocity of each particle and thus its vacuum aerodynamic diameter. The particle is then ablated and ionized with an $8 \mathrm{~ns}$ pulse from a VUV $193 \mathrm{~nm}$ excimer laser (EX5, GAM Laser, Inc.) that is triggered immediately by the second particle light scattering event. The VUV pulse travels coaxially up the particle beam and hits the particle in the ion extraction region, coincident with and orthogonal to the second light scattering laser beam. During these experiments, the $405 \mathrm{~nm}$ scattering lasers were not operational, and instead we free-fired the excimer laser at $10 \mathrm{~Hz}$ with an average laser pulse energy of $2.0 \mathrm{~mJ}$ and an average laser fluence of $\sim 1.1 \times 10^{5} \mathrm{~J} \mathrm{~m}^{-2}$. We set and periodically confirmed the VUV laser power using a laser power meter (EnergyMax, Coherent, Inc.)

The SP2 rapidly heats individual $\mathrm{rBC}$-containing particles as they pass through an intracavity IR laser beam and then measures the intensity of emitted thermal radiation resulting from particle incandescence. The $\mathrm{rBC}$ mass of each particle is proportional to this light intensity. We calibrated the SP2 rBC mass response with fullerene soot that we size-selected using a DMA. We previously measured the batch-specific effective density of this soot sample using a Cambustion centrifugal particle mass analyzer (Gysel et al., 2011; Slowik et al., 2007). We measured the particle concentration dur- 
ing these calibrations using a condensation particle counter (TSI model 3772). Further details are provided by Saliba et al. (2016), where the optical properties of the coated rBC particles produced in these experiments are presented.

Both the SP-AMS and the LAAPTOF use the same aerodynamic lens inlet design (Huffman et al., 2005; Liu et al., 2007). The aerodynamic lens these instruments use efficiently transmit particles with vacuum aerodynamic diameters $\left(d_{\mathrm{va}}\right)$ between 150 and $700 \mathrm{~nm}$. Particles smaller than $150 \mathrm{~nm}$ tend to be removed with the excess gas, while particles greater than $700 \mathrm{~nm}$ may be impacted on the lens' critical orifices. For the measurements presented here, some particles start smaller than $150 \mathrm{~nm} d_{\mathrm{va}}$ and then grow into the ideal lens transmission regime. This is very important for massbased measurements like the SP-AMS, but less so for individual particle analysis for the LAAPTOF. We will discuss how this affects our results in Sect. 3.3.

The aerodynamic lens focuses particles into a collimated beam for transmission into the SP-AMS detection region. The SP-AMS uses the same IR laser as the SP2 to vaporize $\mathrm{rBC}$ along with any internally mixed components; the vapors are then ionized by $70 \mathrm{eV}$ electrons from a tungsten filament and the ions analyzed by time-of-flight mass spectrometry (Canagaratna et al., 2015b; Onasch et al., 2012). The SP-AMS also contains a tungsten heater kept at $600^{\circ} \mathrm{C}$ for particle thermal desorption, identical to the conventional AMS design. Unless stated otherwise, we operated the SPAMS with both the IR laser and the conventional heater on for all experiments described here. The largest uncertainty in mass measurements of $\mathrm{rBC}$ by the SP-AMS is the particle collection efficiency, which is determined by the particle shape and size. The fraction of particles that pass through the laser beam and are vaporized $\left(E_{\mathrm{IR}}\right)$ has been shown to be the largest uncertainty for SP-AMS mass measurements using the IR laser. It is caused by the incomplete overlap of the particle beam and the IR laser beam (Huffman et al., 2005; Onasch et al., 2012; Willis et al., 2014). A perfectly collimated particle beam would result in all of the $\mathrm{rBC}$-containing particles passing through the center of the Gaussian IR laser beam energy profile, where it is most intense. However, the particle beam can spread because small and/or irregularly shaped particles diverge from an ideal beam profile. This divergence is due to Brownian diffusion or uneven drag distribution on the particles as they leave the aerodynamic lens (Huffman et al., 2005; Liu et al., 1995). The collection efficiency for nonrefractory material not mixed with IR laser absorbing $\mathrm{rBC}$ (components that promptly evaporate at $600^{\circ} \mathrm{C}$ ) is determined by the particle bounce off of the heater. Note that the cross-sectional area of the heater is much larger than that of the IR laser beam. Therefore, particle detection of refractory components such as $\mathrm{rBC}$ in the SP-AMS by IR vaporization is more sensitive to particle shape than is the detection of nonrefractory components vaporized by the $600^{\circ} \mathrm{C}$ heater.
We determined the fraction of total particle mass undetected by the SP-AMS due to diverging, light-absorbing particles missing the IR laser beam. We did this by measuring the ion signal from refractory species (elemental carbon or potassium) while sequentially blocking portions of the particle beam with a thin piece of wire $(\varnothing=0.41 \mathrm{~mm})$, called the beam-width probe. We compared the signal with the beamwidth probe in place to the signal observed when the wire was not obstructing any of the particle beam (Huffman et al., 2005; Willis et al., 2014). We show this schematically in Fig. 2 for the carbon cation signal, $\mathrm{C}_{x}^{+}$(where $x$ is a positive integer). The ratio of the partially blocked signal to the unblocked signal, hereafter referred to as the attenuation with the beam-width probe, indicates how narrow the particle beam is. If the measured attenuation is high, then in the absence of the beam-width probe most of the particles will pass through the most intense IR laser region and be vaporized. If the attenuation is low, then some of the particles will miss the laser and the refractory material will not be detected. The IR laser intensity was measured by Willis et al. (2014) to have a Gaussian distribution with a $\sigma \approx 0.18 \mathrm{~mm}$, although this may vary with IR laser power. As the beam-width probe is wider than the effective width of the IR laser for $\mathrm{rBC}$, anything less than complete attenuation of the measured ion signal when the beam-width probe is at the center position indicates that some of the EC mass on particles containing $\mathrm{rBC}$ will not be detected. Therefore, $E_{\mathrm{IR}}$ will be $<1$ (Willis et al., 2014). However, as we will show, vaporization of potassium occurs with a larger effective IR beam width, and thus $E_{\mathrm{IR}}$ is larger for potassium than $\mathrm{rBC}$.

\subsection{Particle mobility measurements and calculations}

During these experiments, there was evidence of subsampling in the aerosol sampling lines, resulting in different particle concentrations reaching some instruments. As a result, we do not compare the absolute concentration of aerosol species measured by the various instruments. Instead, we perform our analysis based on particle size measurements that are unaffected by the flow-splitting issues due to the monodisperse aerosol used here.

We classified the size distribution of the BBA with a scanning mobility particle sizer (SMPS; TSI Inc., model 3081 DMA and 3772 CPC) that measures particle mobility diameter $\left(d_{\mathrm{mob}}\right)$ size distributions and with the SP-AMS that measures particle vacuum aerodynamic diameter $\left(d_{\mathrm{va}}\right)$ in addition to composition. The SP-AMS measures the vacuum aerodynamic diameter by accelerating particles into a vacuum and measuring the time to ion detection after a particle passes through a rotating $2 \%$ slit chopper. We calibrated the particle time of flight measurements using polystyrene latex spheres vaporized using the conventional tungsten heater in the SP-AMS (Jayne et al., 2000). It is important to note that for the fractal-like nascent soot particles, the terms $d_{\text {mob }}$ and $d_{\mathrm{va}}$ do not fully describe the physical shape of a particle. 


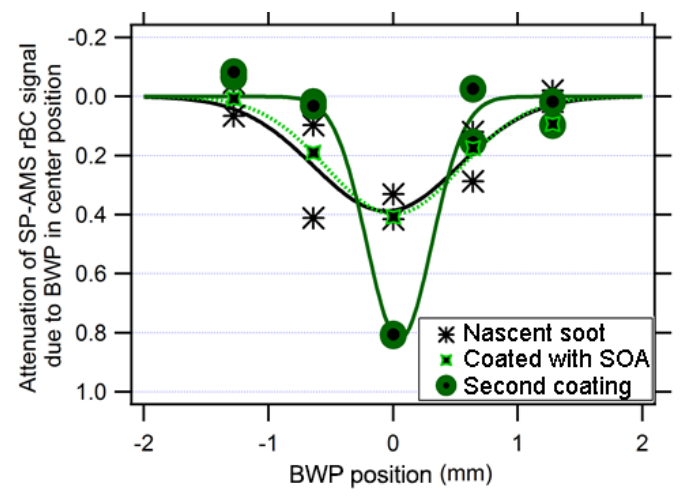

Vertical integration of signal, unblocked and blocked

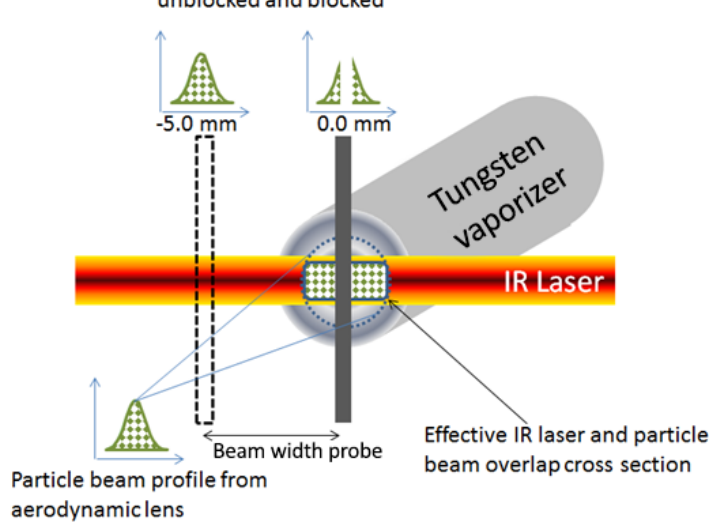

Figure 2. The particle-beam width probe blocks a fraction of the particles that would have been vaporized by the IR laser and thus the probe attenuates the elemental carbon ion signal $\left(\mathrm{C}_{x}^{+}\right)$for $\mathrm{rBC}$ containing particles. We used six probe positions to establish the particle-beam width. The measured ion signal is the integrated Gaussian profile shown at the top of the schematic. The difference between the unblocked $(x=-5.0 \mathrm{~mm})$ and blocked $(0.0 \mathrm{~mm})$ green integrated Gaussian profile plots is the attenuation for that beam width probe blocking position, plotted as the $y$ axis on the top figure. The top panel shows the attenuation of nascent uncoated soot (black asterisks), soot with a single coating of SOA (black and light green crosses), and soot with a second coating of SOA (black and dark green circles). A wider Gaussian particle-beam shape determined by the beam-width probe analysis indicates the aerosol has a small diameter and therefore $E_{\mathrm{IR}}<1$.

Rather, they describe the relationship between the drag force on that particle compared to either a counterbalancing electrostatic force for $d_{\text {mob }}$ or the acceleration modulated by the particle mass for $d_{\mathrm{va}}$ (DeCarlo et al., 2004).

In Fig. 3 we show aerodynamic size distributions for particles originally selected with a DMA at $143 \mathrm{~nm} d_{\text {mob }}$. Though the nascent particles were monodisperse in mobility space, the $d_{\mathrm{va}}$ distribution for the nascent soot particles was much wider than the $d_{\text {mob }}$ distribution. This is probably due to the range of particle masses and shapes that can exist at a given $d_{\text {mob }}$ for highly irregular nascent soot (Zelenyuk et al., 2008). The $d_{\mathrm{va}}$ size range narrowed following the addi-

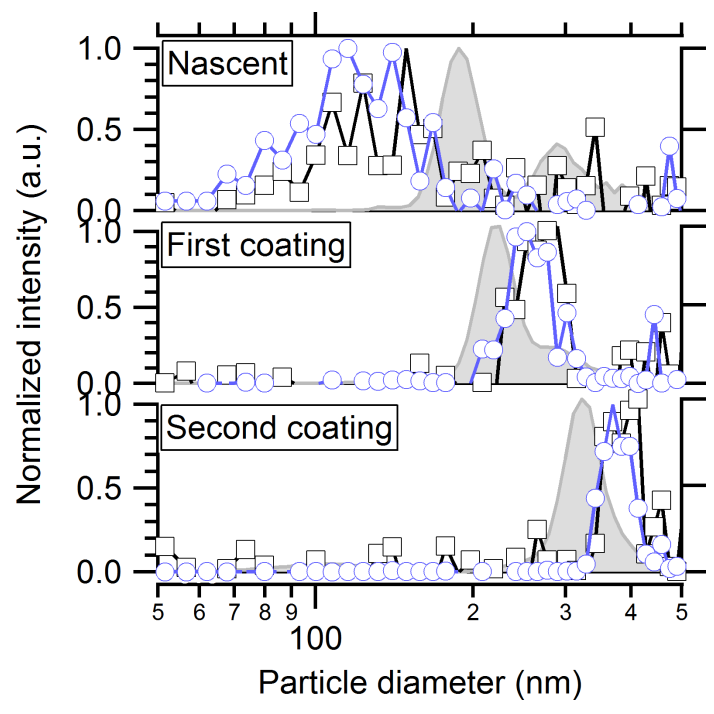

Figure 3. Normalized particle size distributions for coating experiments from two instruments. Traces are mass distributions vs. vacuum aerodynamic diameter $\left(d_{\mathrm{va}}\right)$ for two refractory species measured by the SP-AMS, potassium (purple circles), and rBC (black squares). The filled-in gray curve is the volume distribution $\left(d^{3}\right)$ versus mobility diameter $\left(d_{\text {mob }}\right)$ measured by the SMPS. Measurements of the original uncoated nascent biomass-burning soot particles are shown in the top panel, while the middle and bottom panel show measurements after we applied the first and second SOA coatings, respectively. The uncoated particles had broad mass distributions with modes well below the mobility volume mode, indicating fractal particles with a wide variability in particle shape. The mass distribution narrowed and overtook the volume distribution following condensation of SOA because the particles became more spherical and homogeneous with respect to shape and composition, with a density greater than $1.0 \mathrm{~g} \mathrm{~cm}^{-3}$.

tion of SOA coatings, likely reflecting the increasing uniformity as the irregularly shaped particles became coated with SOA. When measuring the mobility size distribution, we adjusted the sheath flow of the SMPS to ensure that we captured the complete aerosol size distribution, at times operating at sheath-to-sample flow ratios as low as $5: 1$. Although the lower sheath-to-sample flow ratio reduces the SMPS size resolution, it does not affect the accuracy of the mode size determination.

As a nascent soot particle becomes coated with SOA, the particle grows and gains organic mass. Thus $d_{\mathrm{mob}}, d_{\mathrm{va}}$, and the organic mass per particle all increase. We calculated the SOA mass per particle $\left(m_{\mathrm{SOA}}\right)$ from mobility and mass measurements following the method described in Slowik et al. (2004), with some differences as described here. In addition to $d_{\text {mob }}$ and $d_{\text {va }}$, we measured the single-particle black carbon mass $\left(m_{\mathrm{rBC}}\right)$ with the SP2. The SP2 also confirmed that $>97 \%$ of the nascent particles were composed of significant amounts of black carbon. We assumed that the blackcarbon density $\left(\rho_{\mathrm{rBC}}\right)$ was $1.8 \mathrm{~g} \mathrm{~cm}^{-3}$ (Park et al., 2004). For 
thickly coated particles, with $m_{\mathrm{SOA}} \gg m_{\mathrm{rBC}}$, we assumed that the particles were effectively spherical and determined the density of the $\mathrm{SOA}\left(\rho_{\mathrm{SOA}}\right)$ to be $1.3 \mathrm{~g} \mathrm{~cm}^{-3}$ by taking the ratio of $d_{\text {mob }}$ and $d_{\mathrm{va}}$. Knowing the two densities, we then iteratively solved for the particle dynamic shape factor $(\chi)$, volume equivalent diameter $\left(d_{\mathrm{ve}}\right)$, and the average mass of SOA per particle $\left(m_{\mathrm{SOA}}\right)$ using Eqs. (1), (2), and (3) below, taking into account the Cunningham slip correction factor $\left(\mathrm{C}_{\mathrm{c}}\right)$.

$$
\begin{aligned}
& d_{\mathrm{mob}}=\frac{d_{\mathrm{ve}} \mathrm{C}_{\mathrm{c}}\left(d_{\mathrm{mob}}\right) \chi}{\mathrm{C}_{\mathrm{c}}\left(d_{\mathrm{ve}}\right)} \\
& d_{\mathrm{va}}=\frac{d_{\mathrm{ve}}}{\chi\left(\rho_{0}\right)}\left(\frac{m_{\mathrm{rBC}}+m_{\mathrm{SOA}}}{\frac{m_{\mathrm{rBC}}}{\rho_{\mathrm{rBC}}}+\frac{m_{\mathrm{SOA}}}{\rho_{\mathrm{SOA}}}}\right) \\
& \frac{m_{\mathrm{rBC}}}{\rho_{\mathrm{rBC}}}+\frac{m_{\mathrm{SOA}}}{\rho_{\mathrm{SOA}}}=\frac{\pi}{6} \cdot d_{\mathrm{ve}}^{3}
\end{aligned}
$$

We neglected the contribution of ammonium, sulfate, and nitrate to particle mass and volume as they are small $(<10 \%)$ relative to $\mathrm{rBC}$ and SOA. Unless specified otherwise, SOA mass per particle is calculated in this manner. The combustion of solid biomass fuel generates particles with shapes and compositions that vary more widely than those produced from controlled, well-mixed internal-combustion engines (Reid et al., 2005; Schwarz et al., 2008). Relative to engine exhaust soot, biomass-burning particles are typically larger and contain more non-carbonaceous components, such as inorganic salts (Bond et al., 2006; Li et al., 2003; Reid and Hobbs, 1998). Electron microscopy studies of aerosol particles have shown that biomass burning can result in a wide range of particle compositions and morphologies ( $\mathrm{Li}$ et al., 2003; Pósfai and Buseck, 2010). For this work, based on our measurements it appears that most of the particles initially consisted of mostly $\mathrm{rBC}$, with trace primary organic material and inorganic material, including potassium salts. The particles maintained their initial core composition mass as SOA was condensed onto them. This made the particles increasingly homogeneous in terms of composition and shape. Single-particle measurements by the SP2 showed that $>97 \%$ of the particles detected by light scattering contained $>0.7 \mathrm{fg}$ of $\mathrm{rBC}$. In cases where the uncoated, non$\mathrm{BC}$-containing particles were too small to be detected by the SP2 via light scattering, the fraction of $\mathrm{rBC}$-containing particles was monitored after the particles were grown with SOA to detectable sizes. The fraction of $\mathrm{rBC}$-containing particles did not change, except in cases where there was substantial and obvious new particle formation. We suspect that the largest variability in particles was with regard to the amount of potassium in a particle and with respect to particle shape. We do not have an estimate of variability in individual particle potassium content. Variability in particle shape is observed by the broad distribution in vacuum aerodynamic diameters. As the particles became coated, and therefore more uniform in shape and composition, the vacuum aerodynamic diameter distribution narrowed. The coating of fractal-like soot with organics has also been shown to cause structural collapse of the particle, potentially affecting its light absorption cross section (Cross et al., 2010; Ghazi and Olfert, 2013; Zhang et al., 2008).

\section{Results and discussion}

\subsection{Effect of SOA condensation on soot-particle shape}

Figure 4 shows the calculated dynamic shape factor, $\chi$, for particles as they were coated with SOA. Nascent soot particles are very fractal-like, with $\chi>1.6$. This is within the range of previously observed soot from fuel-rich combustion (Slowik et al., 2004). For context, Schwarz et al. (2008) measured the thickness of coatings on ambient BBA using an SP2. The instrument was onboard an aircraft that transected a biomass-burning plume. They determined aged ambient particles with a $\mathrm{rBC}$ core mass equivalent diameter of $200 \mathrm{~nm}$ (BC mass of $8.4 \mathrm{fg}$ ) had a coating thickness of $79 \mathrm{~nm} \sim 1 \mathrm{~h}$ after emission from the biomass-burning source. For comparison, we assume the BBA particles discussed in Schwarz et al. (2008) are coated with SOA with a density of $1.3 \mathrm{~g} \mathrm{~cm}^{-3}$. The SOA coating mass would then be $25.7 \mathrm{fg}$ of OM mass per particle and would result in a mostly spherical particle. Although we cannot say the particle coating observed by Schwarz et al. (2008) consisted entirely of OM mass, the volume equivalent of any secondary component such as sulfate would also result in a spherical particle shape, with a SOA to rBC mass ratio greater than $>3.2$ (Ghazi and Olfert, 2013). As shown before, because the particle shape and size influences the particle-beam profile and the beam width at the IR laser, the shape factor influences the total $\mathrm{rBC}$ signal detected by the SP-AMS.

\subsection{Sequential coating of monodisperse soot in a smog chamber}

In Fig. 5 we display a time series from a particle coating experiment for initially monodisperse particles with $d_{\mathrm{mob}}=$ $143 \mathrm{~nm}$. All of the experiments followed this general pattern. We show the particle mobility size distribution from the SMPS, the rBC mass from the SP2, and the SP-AMS signal for both $\mathrm{rBC}$ and organic material $(\mathrm{OM})$. Prior to coating $(t<0)$, the SP2 and SP-AMS rBC signals decreased as particles were lost to the chamber walls. After each $\alpha$-pinene vapor injection, which drove SOA coating, the particle mobility diameter increased and there was also an increase in the SP-AMS OM signal. After the second injection $(t=0.6 \mathrm{~h})$, the SP-AMS rBC signal increased while the SP2-measured $\mathrm{rBC}$ mass concentration continued to decay, as expected due to particle wall loss. This difference demonstrates that the increase in SP-AMS rBC signal with thicker SOA coatings was almost certainly due to an increase in the IR laser beam particle collection efficiency $\left(E_{\mathrm{IR}}\right)$ of the SP-AMS and not an increase in the actual $\mathrm{rBC}$ mass present in the chamber. 


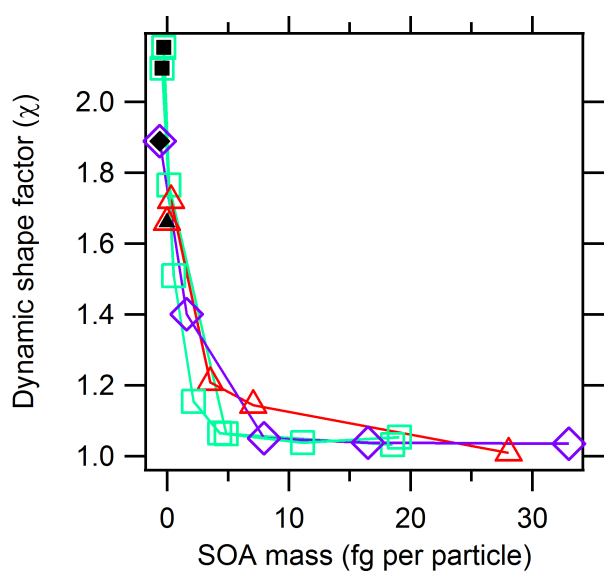

Figure 4. Dynamic shape factor $(\chi)$ of soot particles became more spherical $(\chi \rightarrow 1)$ with increasing SOA mass. Nascent particles (black) were coated sequentially, and after $5 \mathrm{fg}$ of SOA per particle had condensed the particles were mostly spherical in shape. Additional coatings served to increase the diameter of the now effectively spherical particles. Differently colored and shaped symbols indicate different initial selected soot core mobility diameters: red triangles were initially $142 \mathrm{~nm}$, teal squares were $188 \mathrm{~nm}$, and purple diamonds were $220 \mathrm{~nm}$.

\subsection{Particle composition from mass spectrometry}

In Fig. 6 we show speciated high-resolution mass spectra from the SP-AMS for nascent and thickly coated biomassburning particles, detected with the IR laser on. The coating was SOA formed from $\alpha$-pinene ozonolysis. High-resolution peak fitting was done using PIKA version 1.15 (Decarlo et al., 2006). Highly resolved ions were classified into a species and are displayed at unit mass resolution according to the fragmentation table therein. With respect to this dataset, the fragmentation table was only used to adjust the apportioning of $\mathrm{CO}_{2}^{+}$and $\mathrm{C}_{1}^{+}$ions. To account for $\mathrm{CO}_{2}^{+}$in the gas phase vs. particle phase, the fragmentation table was adjusted using HEPA filter gas-only measurements. To account for $\mathrm{C}_{1}^{+}$that may result from the fragmentation of nonrefractory $\mathrm{OM}$ components, the fragmentation table specifies that the amount of $\mathrm{C}_{1}^{+}$attributed to $\mathrm{rBC}$ is limited to $0.625 \cdot \mathrm{C}_{3}^{+}$, the ratio observed for the rBC calibrant, Regal Black (Onasch et al., 2012). Recent studies have begun to investigate the degree to which nonrefractory OM contributes to larger EC ion fragments $\left(\mathrm{C}_{x}^{+}\right.$, where $\left.x>1\right)$ using IR laser vaporization. This has important implications for quantitative measurements of $\mathrm{rBC}$ using the SP-AMS and also for source apportionment based on the ion fragmentation pattern of $\mathrm{rBC}$ (Corbin et al., 2014).

We measured refractory and nonrefractory material from nascent soot using the SP-AMS with the IR laser on. Highresolution analysis of nonrefractory organic material showed significant contribution from aliphatic ions, $\mathrm{C}_{4} \mathrm{H}_{7}^{+}(\mathrm{m} / z+$ 55), $\mathrm{C}_{4} \mathrm{H}_{9}^{+}(m / z+57), \mathrm{C}_{5} \mathrm{H}_{9}^{+}(m / z+69)$, and $\mathrm{C}_{6} \mathrm{H}_{9}^{+}(m / z+$ 81). This is consistent with other AMS measurements of fresh, flaming-phase biomass-burning emissions (Corbin et al., 2015; Cubison et al., 2011; Hennigan et al., 2011). We also observed the highly oxygenated ions $\mathrm{C}_{2} \mathrm{H}_{3} \mathrm{O}_{2}^{+}(\mathrm{m} / \mathrm{z}+$ $60)$ and $\mathrm{C}_{3} \mathrm{H}_{5} \mathrm{O}_{2}^{+}(\mathrm{m} / z+73)$, which are common tracer ions for biomass burning. However, $\mathrm{C}_{2} \mathrm{H}_{3} \mathrm{O}_{2}^{+}$was less than $0.5 \%$ of the total organic signal for nascent soot, much less than what has previously been reported in BBA measurements (Aiken et al., 2010; Corbin et al., 2015; Cubison et al., 2011; Hennigan et al., 2010, 2011; Lee et al., 2010). This is likely due to low cellulose content in the bark that we burned, resulting in less formation of the anhydrosugars including levoglucosan compared to burning wood (Branca et al., 2007). The average oxidation state of carbon $\left(\overline{\mathrm{OS}}_{\mathrm{c}}=2 \mathrm{O}: \mathrm{C}-\mathrm{H}: \mathrm{C}\right)$ for the organic fragments (including $\mathrm{HO}^{+}, \mathrm{H}_{2} \mathrm{O}^{+}$, and $\mathrm{CO}_{2}^{+}$) was $-0.56 \pm 0.25$. This low oxidation state is consistent with primary organic aerosol (Canagaratna et al., 2015a; Kroll et al., 2011). We also observed refractory material, including elemental carbon series $\left(\mathrm{C}_{1}^{+}-\mathrm{C}_{9}^{+}\right)$and some metals including potassium, rubidium, and zinc. The alkali metals have very low ionization energies, and thus may become ionized by heating in the IR laser. This ionization mechanism is independent of the $70 \mathrm{eV}$ electrons that usually ionize neutral vapors in the SP-AMS. A broad abnormal ion peak shape of the metals indicates that they underwent single-step thermal ionization in the IR beam, rather than conventional twostep thermal vaporization with subsequent electron ionization (Allan et al., 2004; Carbone et al., 2015; Corbin et al., 2015; Drewnick et al., 2006). Condensation of SOA from $\alpha$ pinene ozonolysis increased the signal from most organic fragments. Especially notable was the signal increase for singly oxygenated organic fragments $\mathrm{C}_{2} \mathrm{H}_{3} \mathrm{O}^{+}(\mathrm{m} / z+43)$, $\mathrm{C}_{3} \mathrm{H}_{3} \mathrm{O}^{+}(m / z+55), \mathrm{C}_{4} \mathrm{H}_{7} \mathrm{O}^{+}(m / z+71)$, and $\mathrm{C}_{5} \mathrm{H}_{7} \mathrm{O}^{+}$ $(m / z+83)$. Reduced fragments such as $\mathrm{C}_{5} \mathrm{H}_{9}^{+}(m / z+69)$ also increased with SOA coating. After a thick coating (with an SOA : BC mass ratio of approximately 9) the average oxidation state of carbon was $1.15 \pm 0.04$. This is consistent with the $\alpha$-pinene ozonolysis SOA formed in smog chambers (Chhabra et al., 2010; Shilling et al., 2008); however, the SOA mass spectra we obtain show relatively less fragmentation than similar $\alpha$-pinene SOA mass spectra obtained with a conventional AMS using the $600^{\circ} \mathrm{C}$ heater. This suggests that a significant fraction of the particles were vaporized by the IR laser ( $>97 \%$ of the BBA contained sufficient black carbon that could be measured by the SP2) and that this produced marginally less fragmentation; the much lower $f_{44}$ (fraction of total ion signal at $m / z+44$ ) is also consistent with this hypothesis. Canagaratna et al. (2015b) used nearthreshold VUV ionization with a SP-AMS to confirm that ionization via the IR laser resulted in significantly less fragmentation for pure components, relative to when vaporized by the $600^{\circ} \mathrm{C}$ heater.

Attribution of $\mathrm{rBC}$ in the SP-AMS mass spectrum would be straightforward if graphitic material had a consistent fragmentation pattern and if all elemental carbon fragments 


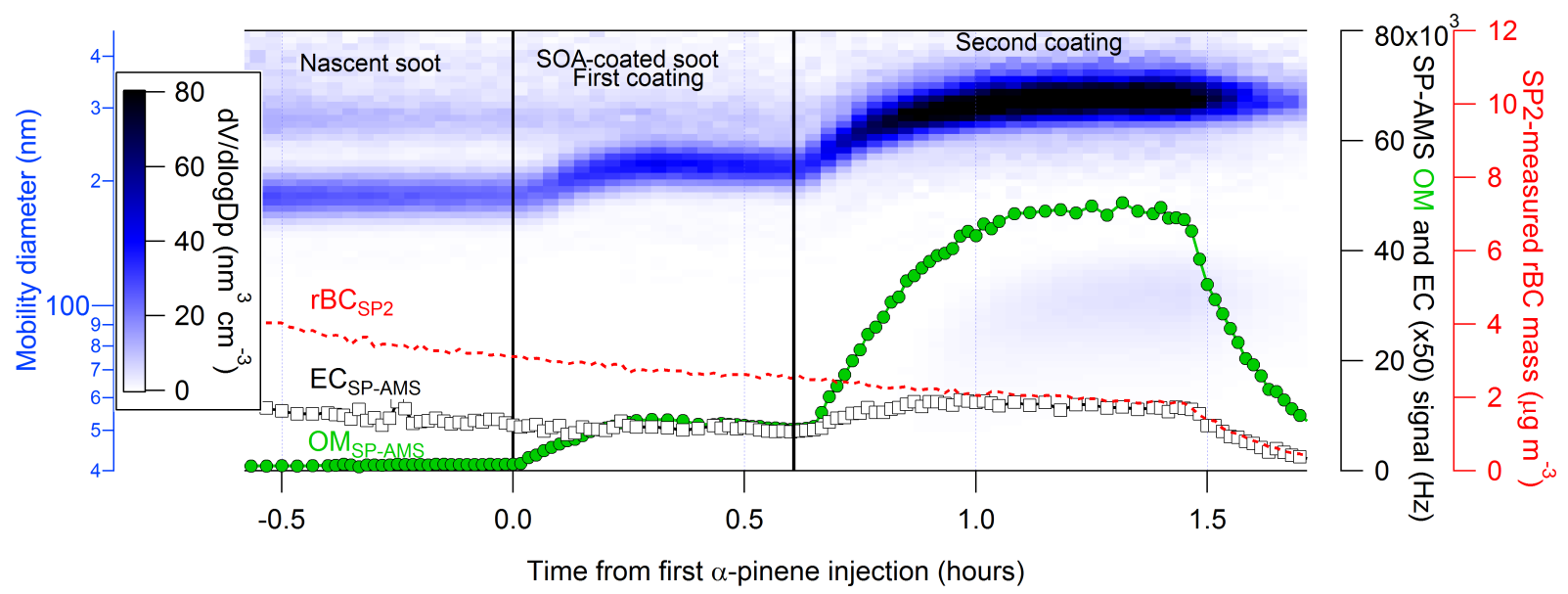

Figure 5. Monodisperse biomass soot particles to which two successive additions of SOA were applied. Fractal-like, monodisperse soot particles with initial mobility diameter of $143 \mathrm{~nm}$ grew via condensation of successive SOA coatings following discrete injections of $\alpha$-pinene vapor (indicated by vertical lines) into a chamber containing ozone. Particle growth is evident in the volume-weighted SMPS mobility size distribution (blue-black, top) and the SP-AMS measured OM (green closed circles) and EC (black open squares) ion signal as a function of time. SP2 rBC mass measurements (red dotted line) reveal the steady decay of soot-particle mass concentration due to chamber wall loss, followed by greater loss when we purged the chamber at $t>1.5 \mathrm{~h}$.

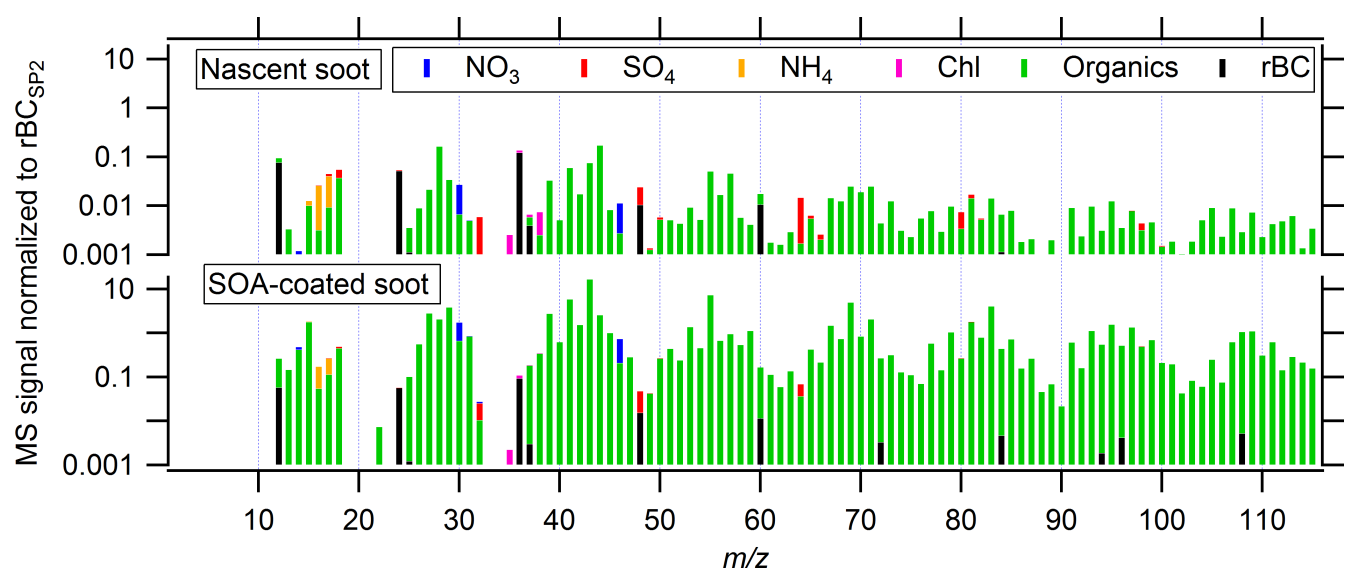

Figure 6. Stick integrated high-resolution mass spectra from the SP-AMS for nascent (top) and thickly SOA-coated soot (bottom). Mass spectra were collected with the IR laser on and have been normalized by total rBC mass as measured by the SP2 to account for particle wall loss. Peak bar colors correspond to the assigned chemical components for each unit $\mathrm{m} / \mathrm{z}$ ion peak, based on analysis of the highresolution mass spectra. The nascent soot spectrum is rich in refractory black carbon, inorganic ions, and organic fragments. The spectrum from the SOA-coated soot, however, is dominated by the OM from the secondary organic aerosol. However, increased sensitivity to larger $\mathrm{EC}$ fragments from $\mathrm{rBC}$ in the coated particles is obvious.

(the $\mathrm{C}_{x}^{+}$family) arose only from $\mathrm{rBC}$. However, studies using high-resolution transmission electron microscopy (HRTEM) have shown that rBC can have varying degrees of disorder that result from formation conditions (Vander Wal and Tomasek, 2004). Onasch et al. (2015) showed the IR laser in the SP-AMS may cause restructuring of the $\mathrm{rBC}$ due to annealing. Annealing has been observed in other graphitic particle systems using HR-TEM and a pulsed laser (Vander Wal and Choi, 1999; Vander Wal and Jensen, 1998). It is also well known that organic matter produces $\mathrm{C}_{1}^{+}$and $\mathrm{C}_{2}^{+}$fragments following electron ionization (Alfarra, 2004; Corbin et al., 2014), but we have evidence that SOA either produces larger $\mathrm{C}_{x}^{+}$fragments or changes the rBC fragmentation pattern. In Fig. 7 we show the ion peak area ratios for $\mathrm{C}_{4}^{+} / \mathrm{C}_{3}^{+}$and $\mathrm{C}_{6-9}^{+} / \mathrm{C}_{3}^{+}$for size-selected soot particles as they became coated with SOA. The SOA mass per particle on the $x$ axis is the mass calculated from particle size measurements, described in Sect. 2.3. Both ratios increase consistently with coating mass, with a larger slope for smaller cores (with smaller $m_{\mathrm{rBC}}$ ). This is also apparent in Fig. 6, where black sticks representing EC from $\mathrm{rBC}$ are evident for $m / z \geq 72$ after SOA coating, while they were not detected 


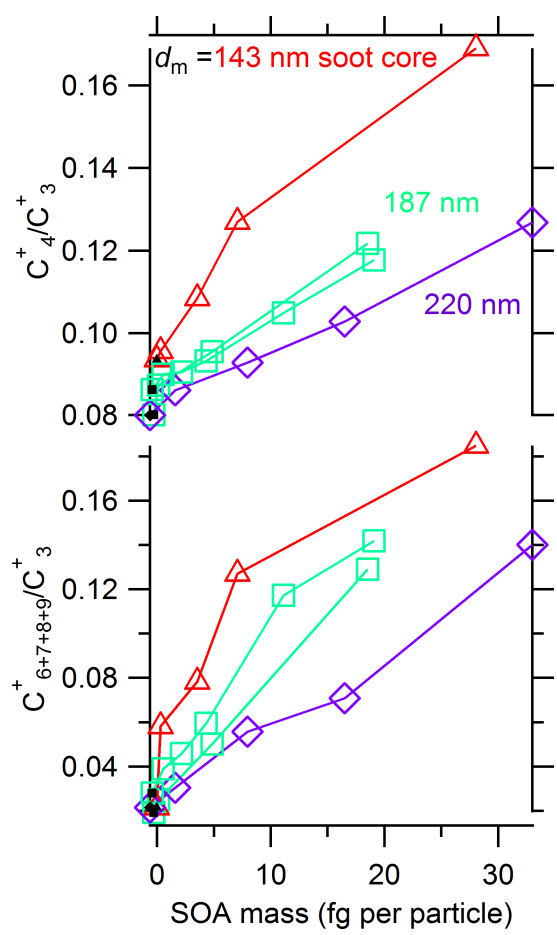

Figure 7. SP-AMS measurements of carbon ion family $\left(\mathrm{C}_{x}^{+}\right)$peak area ratios versus SOA coating mass on three different BBA soot core sizes, indicated by symbol colors. SOA mass determined from SP-AMS measurements of all identified OM mass (as in Fig. 4). The ratio of $\mathrm{C}_{4}^{+}$and $\mathrm{C}_{\sum{ }^{+}{ }_{-9}}^{+}$compared to $\mathrm{C}_{3}^{+}$increases with organic coating due to either contributions to the $\mathrm{C}_{x}^{+}$family from nonrefractory $\mathrm{OM}$ or a decrease in relative fragmentation of $\mathrm{EC}$ to $\mathrm{C}_{3}^{+}$.

in the nascent soot. We propose three possible explanations for these trends: (1) SOA coating changes the fragmentation pattern of EC to reduce the $\mathrm{C}_{3}^{+}$signal, thereby enhancing the apparent ratio of other EC ions relative to it; (2) SOA generates significant signal for $\mathrm{C}_{>3}^{+}$; or (3) the abundant signal at the same nominal masses as $\mathrm{C}_{>5}^{+}$causes the $\mathrm{HR}$ peak fitting to incorrectly attribute some signal to $\mathrm{C}_{>5}^{+}$. During $\mathrm{HR}$ peak fitting, the user decides whether to include an ion based on the residual signal. The residual signal is the amount of measured signal that is not reproduced by the fitted HR ion species. Although the addition of the higher $\mathrm{C}_{x}^{+}$fragments appear to reduce the residual signal, the peak fitting without them is still very good (residual $<0.05 \%$ ). Furthermore, the signal at $\mathrm{C}_{1}^{+}-\mathrm{C}_{5}^{+}$is much higher and better resolved in the peak fitting due to fewer available peaks to fit. Although the causes of these trends are not clear, the trends themselves indicate that soot source apportionment by the SP-AMS might be most meaningful for $\mathrm{rBC}$ that has been thermally denuded to remove any coatings as this would remove any effect of $\mathrm{OM}$ on the $\mathrm{C}_{x}^{+}$ratios measured from the $\mathrm{rBC}$.

We detected small amounts of nonrefractory species other than OM, amounting to less than $10 \%$ of the total mass. Ammonium sulfate condensed onto the particles after they were injected into the chamber. This was probably caused by the formation of sulfuric acid from oxidation of $\mathrm{SO}_{2}(\mathrm{~g})$ and subsequent neutralization by ammonia in the dry chamber. We also detected nitrate ions after addition of ozone to the chamber, as well as after injections of $\alpha$-pinene, suggesting the formation of some organonitrates (Farmer et al., 2010; Zhang et al., 2006). The $\mathrm{NO}^{+} / \mathrm{NO}_{2}^{+}$ratio was 2.2 , as opposed to 1.45 for ammonium nitrate calibration particles. We observed chloride with both SP-AMS vaporizer modes (IR laser on and off), while the potassium signal was much larger when we operated the SP-AMS with the laser on. This is further evidence that the potassium is internally mixed with black carbon and that it underwent one-step thermal ionization in the IR beam (Corbin et al., 2015; Drewnick et al., 2006; Lee et al., 2016). Sulfur dioxide, ammonia, nitrogen oxides, hydrogen chloride, and chloride salts are known common primary emissions from biomass burning (Levin et al., 2010; Li et al., 2003; Reid et al., 2005; Stockwell et al., 2015; Zauscher et al., 2013).

Figure 8 shows single-polarity mass spectra obtained by the LAAPTOF for individual particles before and after coating with SOA. The characteristic ion series for elemental carbon included $\mathrm{C}_{1}^{+}, \mathrm{C}_{2}^{+}$, and $\mathrm{C}_{3}^{+}$. We also observed anions $\mathrm{C}_{1}^{-}$ and $\mathrm{C}_{2}^{-}$for some particles, but not as consistently. We observed $\mathrm{NO}^{+}$in both coated and uncoated particles. We believe that this may be the result of $\mathrm{NO}_{x}$ and $\mathrm{O}_{3}$ combining in the chamber and forming $\mathrm{NO}_{3}$ radicals. These $\mathrm{NO}_{3}$ radicals may then react with water or organic vapors to form $\mathrm{HNO}_{3}$ or organonitrates, respectively. Either species could then condense onto the existing particles and fragment to $\mathrm{NO}^{+}$in the mass spectrometers. $\mathrm{K}^{+}$was readily identified by its isotopic abundance at $m / z+39$ and +41 (Bahadur et al., 2010; Healy et al., 2012; Silva et al., 1999). OM fragments tentatively identified as $\mathrm{CO}^{+}$at $m / z+28$ and $\mathrm{C}_{2} \mathrm{H}_{3} \mathrm{O}^{+}$at $m / z+43$ were measured from both nascent and oxidized particles. We also observed sulfur and sulfate ions $\left(\mathrm{S}^{+}, \mathrm{SO}^{+}\right.$, and $\left.\mathrm{HSO}_{4}^{-}\right)$, likely fragments of sulfates. $\mathrm{Zn}^{+}$was observed and identified by its isotopic fingerprint.

As previously stated, for these experiments the instrument was operated in UV laser free-fire mode, without the aid of light scattering modules to more efficiently detect particles and trigger the excimer. As a result, only 454 individual mass spectra were collected by the LAAPTOF across the four experiments. Of 454 particles, 31 contained only potassium and inorganic species, with no detectable elemental carbon; 4 of 454 particles contained $\mathrm{S}^{+}$or $\mathrm{SO}^{+}$. Of the 454,11 had a negative ion mass spectrum in addition to a positive ion mass spectrum; 5 of these negative ion spectra contained only $\mathrm{HSO}_{4}^{-}, 2$ were only $\mathrm{C}_{1}^{-}$, and the remaining were a richer spectrum of elemental carbon with larger signal from even carbon number anions, consistent with previous observations (Bloomfield et al., 1985; Onasch et al., 2015). Of 454 particles, 104 contained $\mathrm{Zn}^{+}$and 281 particles contained $\mathrm{NO}^{+}$. 


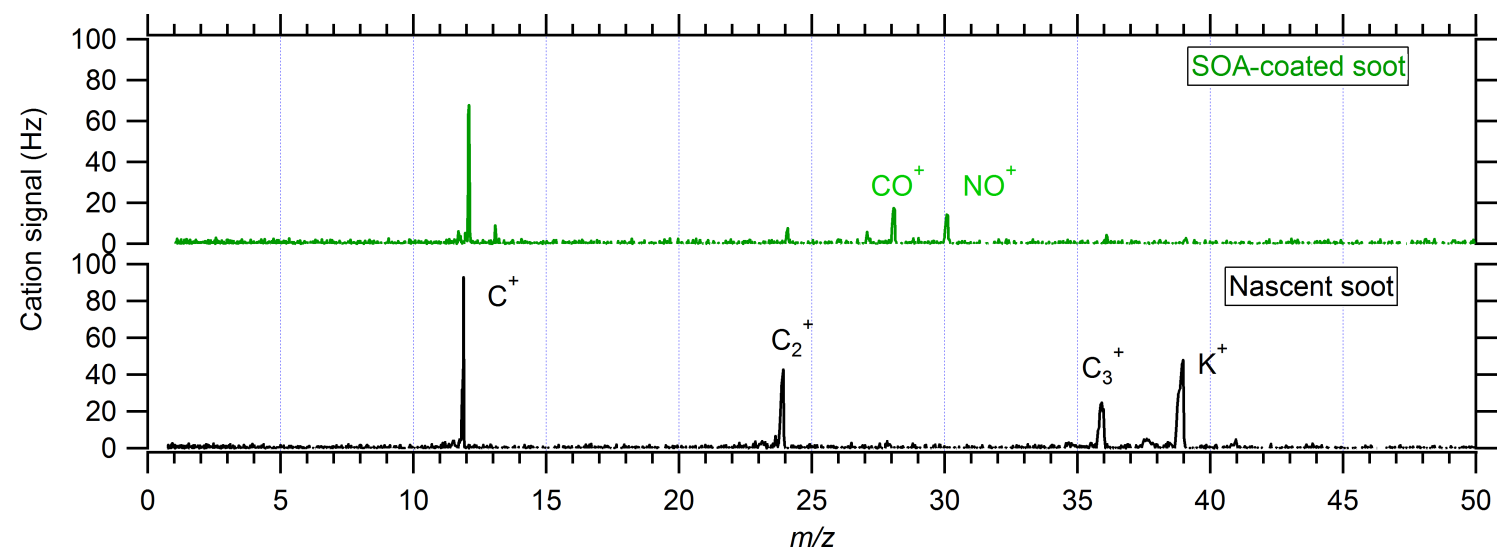

Figure 8. Positive polarity mass spectra and ion assignments for two representative particles analyzed by the LAAPTOF. The elemental carbon fragment series $\left(\mathrm{C}_{x}^{+}\right)$dominates the nascent soot spectra in the bottom, while the contribution from oxidized organic matter is increased in the top panel for a soot particle that was coated with $\alpha$-pinene SOA.

\subsection{SP-AMS sensitivity to refractory species}

We determined the ion response of the SP-AMS to biomassburning particles as a function of SOA coating mass using two ions produced from refractory biomass-burning material $-\mathrm{K}^{+}$and $\mathrm{C}_{3}^{+}$- normalized by the $\mathrm{rBC}$ mass concentration measured by the SP2 $\left(\mathrm{rBC}_{\mathrm{SP} 2}\right)$. In Fig. 9 we show the $\mathrm{K}^{+}$ and $\mathrm{C}_{3}^{+} \mathrm{SP}$-AMS ion signal per $\mathrm{rBC}_{\mathrm{SP} 2}$ mass during progressive SOA coating experiments. The plotted points are $10 \mathrm{~min}$ averages for four batch chamber experiments using different initial soot core sizes. We determined the SOA mass per particle using the method described in Sect. 2.3. Different colored and shaped traces indicate the mobility mode diameter of the initial soot core injected into the chamber, and the black dots indicate the initial nascent soot, prior to SOA coating. We used the SP2-measured rBC mass to correct for particle wall loss in the chamber because the rBC mass measurement of the SP2 is insensitive to particle shape and coating thickness for particles with at least $0.7 \mathrm{fg}$ of $\mathrm{rBC}$ present (Schwarz et al., 2010). The smallest particle mode measured in these experiments was $1.1 \mathrm{fg}$ of $\mathrm{rBC}$, well above detection limits for the SP2. All of the wall-loss-corrected ion signals in Fig. 9 were also normalized to the uncoated soot conditions. This was done for three reasons. First, the inherent variability in biomass burning limits how much one can expect uncoated soot particles to have similar amounts of $\mathrm{K}$ or rBC. However, within a given coating experiment, the average composition of the soot-particle core is guaranteed to be the same. Second, it allows for ready comparison of the data in Figs. 9 and 10, which compares the changes in the two ions directly. Finally, the normalization is a small change relative to the effect induced by coating the soot particles with SOA, which is the focus of this work. Prior to normalization, initial wall-loss-corrected values for $\mathrm{C}_{3}^{+}\left(\mathrm{K}^{+}\right)$for nascent conditions agreed within $30 \%(20 \%)$, compared to the sometimes $300 \%(600 \%)$ change due to coating the particles with SOA.
Potassium is a useful marker for refractory BBA material because it has a high signal-to-noise ratio, it is not produced by fragmentation of nonrefractory $\mathrm{OM}$, and it is a nonvolatile unreactive conserved tracer. By turning off the IR laser we confirmed that very little of the potassium signal resulted from particles that hit the conventional $600{ }^{\circ} \mathrm{C}$ heater $(<1 \%$ of total $\mathrm{K}^{+}$signal with IR laser on). Therefore, the potassium we observed with the IR laser on was internally mixed with $\mathrm{rBC}$. We selected $\mathrm{C}_{3}^{+}$at $m / z+36$ as an ion of interest because of its large contribution to the total $\mathrm{rBC} \mathrm{C}_{x}^{+}$family signal (Fig. 4) and the very low contribution from OM. The $\mathrm{C}_{3}^{+}$signal from OM is less than $0.08 \%$ of the total OM signal when the IR laser is off and particles are vaporized by the heater. One important difference between the two measured species, $\mathrm{K}^{+}$and $\mathrm{C}_{3}^{+}$, is the method of ion formation within the SP-AMS. rBC undergoes the conventional process of IR vaporization followed by $70 \mathrm{eV}$ electron ionization of neutral vapors. Potassium, however, has a very low ionization energy and at high temperatures can undergo one-step thermal ionization, without interacting with $70 \mathrm{eV}$ electrons to become ionized (Corbin et al., 2015; Drewnick et al., 2006; Svane et al., 2004; Zandberg, 1995). Furthermore, rBC particles approach $\sim 4000 \mathrm{~K}$ in the IR laser before vaporizing, while potassium may vaporize or ionize at temperatures less than $1500 \mathrm{~K}$ (Svane et al., 2004).

Panels a and e in Fig. 9 reveal an increasing SP-AMS response to both potassium and $\mathrm{rBC}$ as the SOA coating grew. Panels $b$ and $f$ show the attenuation of the $\mathrm{K}^{+}$or $\mathrm{C}_{3}^{+}$ion signal normalized to SP2-measured $\mathrm{rBC}$ that resulted from moving the beam-width probe into the center of the particle beam. The attenuation increased as the SOA coating thickened because the particle beam narrowed. The increased response of the SP-AMS with successive coatings of SOA is thus due to an increase in the SP-AMS IR-beam particle collection efficiency, $E_{\mathrm{IR}}$. However, the attenuation of $\mathrm{K}^{+}$rises 

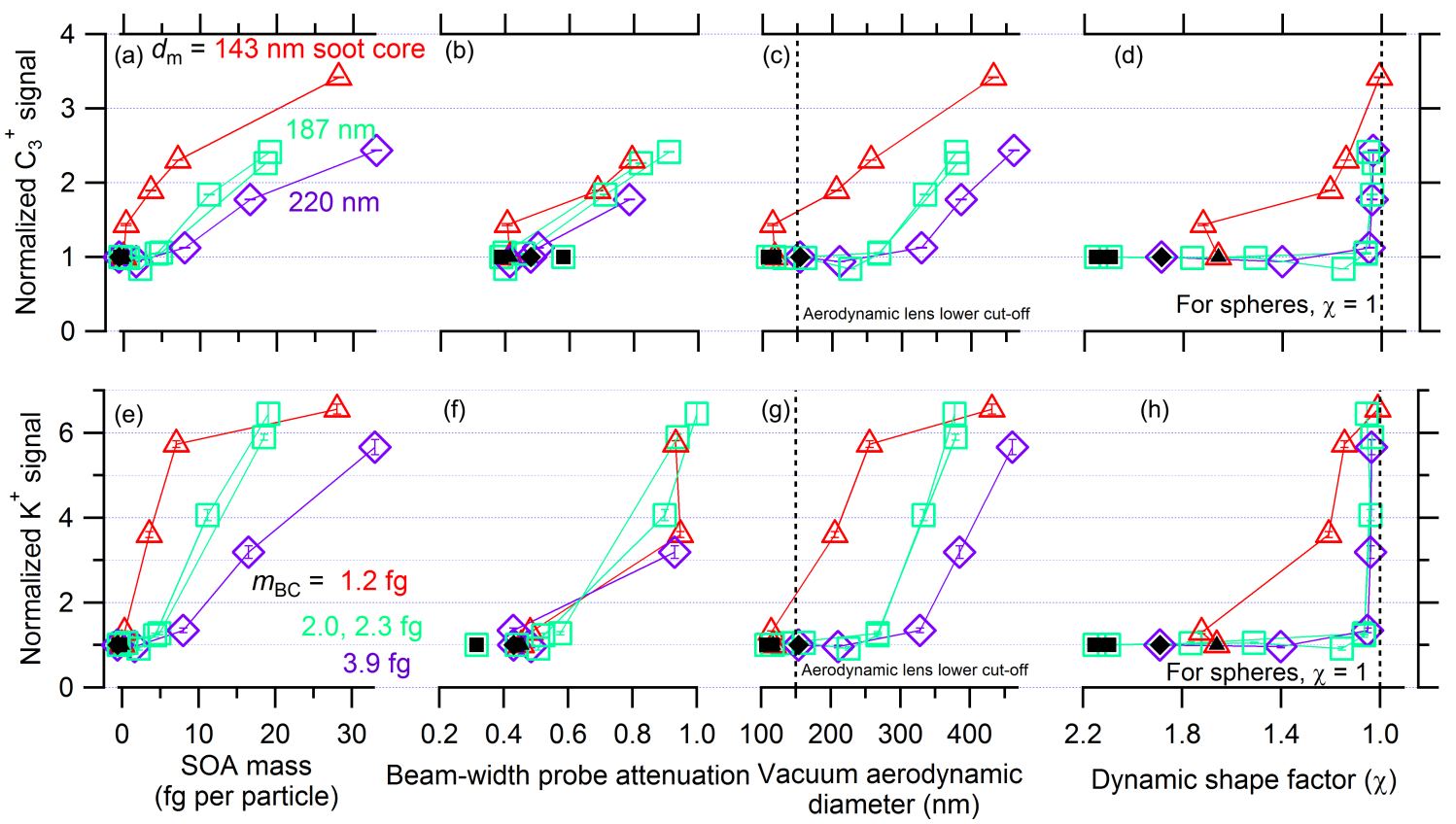

Figure 9. SP-AMS-measured biomass-burning ion signals for $\mathrm{C}_{3}^{+}$(top) and $\mathrm{K}^{+}$(bottom) for three mobility-selected core particle sizes versus four different metrics. These signals are corrected for particle wall loss using SP2-measured $\mathrm{rBC}$, and then normalized to values obtained from the uncoated nascent soot. Symbols are colored/shaped by their initial soot core mobility diameter (SP2-measured rBC mass per particle), prior to SOA coating, where red triangles indicate $143 \mathrm{~nm}(1.2 \mathrm{fg})$, teal squares indicate $187 \mathrm{~nm}(2.0,2.3 \mathrm{fg}$, two replicate experiments), and purple diamonds indicate $220 \mathrm{~nm}(3.9 \mathrm{fg})$. The nascent particles are indicated by black dots, and the lines connect them with the data points following subsequent SOA coatings. The left panels (a, e) display the normalized ratio of the SP-AMS-measured $\mathrm{C}_{3}^{+}$ and $\mathrm{K}^{+}$ion signals, respectively, to the SP2-measured black carbon mass concentration as a function of the mass of SOA per particle. The SP-AMS-measured ion to SP2-measured $\mathrm{rBC}$ mass ratio is normalized to the uncoated soot values. Panels (b, $\mathbf{f})$ display the attenuation of the SP-AMS ion signal caused by the beam-width probe in the center of the particle beam; greater attenuation indicates a more collimated, narrow particle beam, as expected for particles that are larger and/or more spherical. Panels (c, g) display the mode mobility diameter of the particles that produced either the $\mathrm{C}_{3}^{+}$or $\mathrm{K}^{+}$ion signal. The vertical dashed line indicates the lower size cutoff for the aerodynamic lens. Panels $(\mathbf{d}, \mathbf{h})$ display the particle dynamic shape factor; particles start as less spherical $(\chi>1.0)$ and move towards sphericity $(\chi=1)$ as more SOA mass is added. The measurement uncertainties are indicated by the vertical error bars and represent the standard deviation of 1 min AMS integration time from the $10 \mathrm{~min}$ averages presented by each symbol.

steeply, whereas the attenuation of $\mathrm{C}_{3}^{+}$steadily continues to rise more shallowly with coating thickness.

The IR laser beam cross section that vaporizes particles has a roughly Gaussian intensity profile. The difference we observe between $\mathrm{C}_{3}^{+}$and $\mathrm{K}^{+}$attenuation suggests that the effective IR beam for vaporizing $\mathrm{rBC}$, described by Willis et al. (2014), is narrower than the effective beam for thermal ionization of potassium. That is, $\mathrm{rBC}$ must pass through a region of higher laser energy density near the center of the IR beam to be vaporized, ionized by the electron source, and then detected, relative to the lower laser energy density that is required for thermal ionization of potassium. If an internally mixed particle containing potassium and $\mathrm{rBC}$ passes through the center of the laser, two processes will take place. $\mathrm{rBC}$ will become vaporized and ionized, and potassium will be thermally ionized. Since turning off the IR laser reduced the potassium signal to $<1 \%$ of that when the laser was on, we know that the observed changes in $\mathrm{K}$ signal result from $\mathrm{rBC}$ particles internally mixed with some K. Thus, our measure- ments show that particles may pass through the potassium thermal ionization region of the IR beam but miss the smaller $\mathrm{rBC}$ vaporization region.

The ability of an aerodynamic lens, such as that used on the SP-AMS, to effectively focus a particle depends on particle morphology. Panels $\mathrm{c}$ and $\mathrm{g}$ in Fig. 9 illustrate the increasing response of the SP-AMS to coated $\mathrm{rBC}$ as a function of vacuum aerodynamic diameter. The increasing response is likely due to the product of the aerodynamic lens transmission efficiency and the overlap between the particle beam and the IR laser, $E_{\mathrm{IR}}$. However, it appears that the largest increase in particle sensitivity occurs when the particle $d_{\mathrm{va}}$ increases beyond $200 \mathrm{~nm}$. The lower size cutoff of the aerodynamic lens is $150 \mathrm{~nm}$, as discussed in Sect. 2.2 and illustrated by a black dotted line in Fig. 9c and g. Any changes in sensitivity for $d_{\mathrm{va}}>150 \mathrm{~nm}$ are therefore minimally affected by particle lens transmission. The particles grow as more SOA mass is condensed, and the larger particles are focused more efficiently by the aerodynamic lens towards the center of the 
IR laser, resulting in a larger instrument ion signal response with both increasing particle size and increasing SOA mass. The other factor that influences effective focusing of the particles in an aerodynamic lens is particle shape, reported as a calculated dynamic shape factor, $\chi$. As seen in panels $\mathrm{d}$ and $h$, the shape factor decreases towards unity $(\chi=1$ for spheres) as the particles become more thickly coated with SOA. Although the particles become nearly spherical after a few coatings, they still need to grow to a sufficiently large diameter to be successfully focused into the IR laser beam of the SP-AMS. Neither particle shape nor diameter alone is sufficient to describe $E_{\mathrm{IR}}$. Even at $d_{\mathrm{va}}=250 \mathrm{~nm}$ there is a factor of 2 difference in response to particles with different dynamic shape factors. However, the largest increase in instrument response occurs after the particles are mostly spherical $(\chi<1.2)$, which as we discussed in Sect. 2.3 may describe the state of $\mathrm{rBC}$ particles in ambient biomass-burning plumes after less than $1 \mathrm{~h}$ of aging. This increase in instrument signal is driven by growth from condensation of additional SOA. Panels $d$ and $h$ demonstrate this by plotting the refractory ion signal ratios versus the dynamic shape factor $(\chi)$ calculated as described in Sect. 2.3.

Figure 10 shows the same normalized $\mathrm{K}^{+}$and $\mathrm{C}_{3}^{+}$signals from Fig. 9, accounting for particle wall loss and normalized to the ion response under nascent conditions. The differently shaped and colored traces show the relative enhancement of ion signals, measured for the same SOA coating conditions. The greater increase in the $\mathrm{K}^{+}$signal compared to the increase in the $\mathrm{C}_{3}^{+}$ion signal for the same coatings is attributed to two distinct ion formation mechanisms that the two species experienced. As the IR laser has a Gaussian intensity profile, the different mechanisms occur in different regions of the IR beam. Evidently, a higher intensity is necessary for the vaporization of $\mathrm{rBC}$, but a lower intensity can still drive thermal vaporization/ionization of alkali metals, such as potassium and sodium. The Gaussian IR beam thus has a greater effective width for alkali metals than for rBC.

Figure 11 displays the wall-loss-corrected $\mathrm{K}^{+}$and $\mathrm{C}_{x}^{+}$signal measured by the SP-AMS as a function of wall-losscorrected OM signal. We corrected the SP-AMS signal for wall losses using the rBC mass measurement from the SP2, and we normalized the signals from each experiment to the signals for the nascent soot particles. We smoothed the traces using a three-point boxcar moving average to clarify trends. The OM signal is not quantitative due to unknown relative ionization and collection efficiencies for organics detected with both the IR laser and heater operating simultaneously. However, it provides a high-time-resolution relative metric of the amount of condensed SOA. It shows that even at our highest achieved coating thickness the signals from both $\mathrm{K}^{+}$ and $\mathrm{C}_{x}^{+}$continued to increase; neither signal saturated. This is different from what is expected based on the results of Willis et al. (2014). When they coated Regal Black with OM in the form of DOS, they observed that both OM ions and

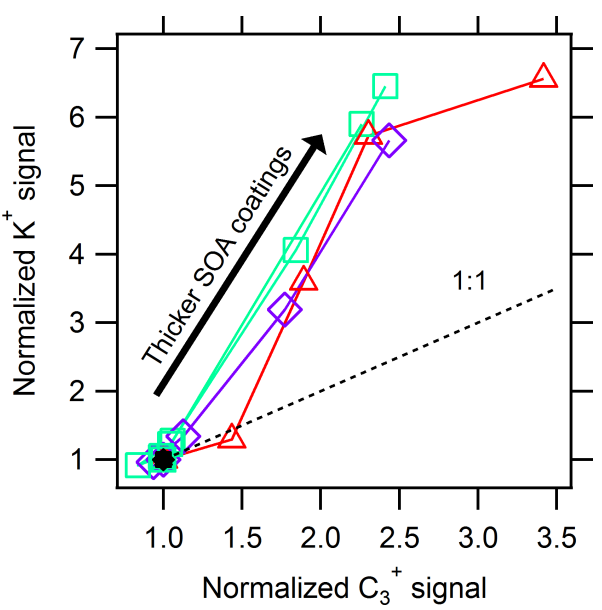

Figure 10. Correlation of refractory ion signals from the SP-AMS during SOA coating experiments. Colored symbols represent the relative enhancement of $\mathrm{K}^{+}$and $\mathrm{C}_{3}^{+}$, as in Fig. 9. All four traces, indicating different coating experiments, begin at $(1,1)$ and generally increase with increasing SOA coating. The increase in measured $\mathrm{K}^{+}$compared to $\mathrm{C}_{3}^{+}$ion signal for the same coatings shows that there are two different effective laser widths for the processes: thermal ionization of $\mathrm{K}^{+}$and two-step vaporization-ionization of $\mathrm{rBC}$.

EC ions reached a maximum enhancement after coating the Regal Black with a thick coating of DOS (OM mass : EC mass $>3$.) Although we cannot rule out the effect of $E_{\mathrm{IR}}$, the continued increase merits investigation of other causes for increased ion signals with additional SOA coating.

The continuous increase in $\mathrm{K}^{+}$ion signal may potentially be explained by changes in the thermal ionization efficiency, described by the Saha-Langmuir equation (Zandberg and Ionov, 1971). This states that the probability of thermal ionization of a species will increase if the surface it vaporizes from has a higher work function or reaches a higher temperature. One explanation is that the highly oxygenated SOA possesses a higher work function than the rBC, and thus as the particle is coated it may generate potassium ions more efficiently. However, it seems unlikely that potassium would vaporize before all the SOA, as is seen in similar, albeit ambient pressure, IR laser systems (Moteki and Kondo, 2007; Schwarz et al., 2010; Stephens et al., 2003). An alternative explanation is that thicker SOA coatings may cause the particle to penetrate deeper into Gaussian profile of the IR laser before the potassium vaporizes and it subsequently vaporizes from a hotter surface, thus generating more ions thermally.

With respect to the increasing $\mathrm{C}_{x}^{+}$signal with increasing coating thickness, a potential explanation includes the fragmentation of SOA to contribute significantly to $\mathrm{C}_{x}^{+}$mass. As stated in Sect. 3.4, laser-off measurements of the SOA showed that $\mathrm{C}_{3}^{+}$accounted for $0.08 \%$ of the SOA mass. With an OM mass increase of 10 times the $\mathrm{rBC}$ present in a particle, and assumed relative ionization efficiencies for 


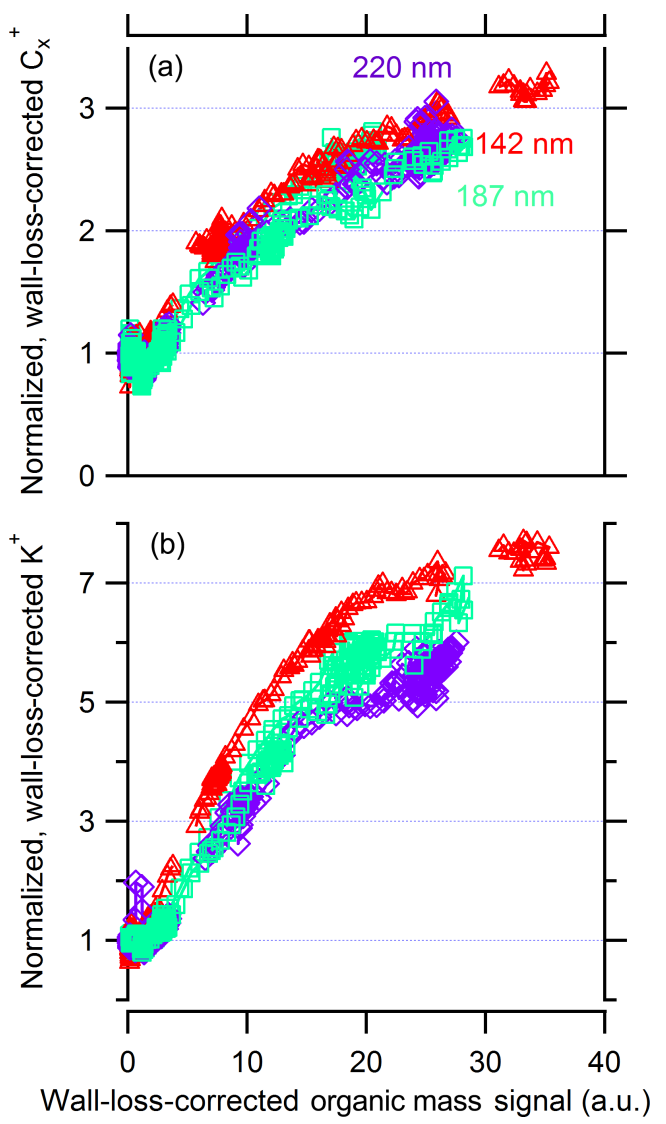

Figure 11. Wall-loss-corrected SP-AMS signal from $\mathrm{rBC} \mathrm{C}_{x}^{+}$ (panel a) and $\mathrm{K}^{+}$(panel b) have been normalized to their nascent values (before SOA coating) and are shown as a function of wallloss-corrected SP-AMS OM signal. Marker shapes and sizes indicate the initial soot core mobility diameter for a given experiment. One-minute averages show that the evolution of the particle sensitivity is continuous and, even at our thickest SOA coating, we continue to see an increase in instrument sensitivity to both $\mathrm{rBC}$ and $\mathrm{K}$ refractory material.

$\mathrm{rBC}$ and $\mathrm{OM}$ of 0.2 and 1.4 , respectively, the perceived increase in EC that would be attributed incorrectly would be $1.1 \%$. This is much smaller than the observed relative increase in $\mathrm{C}_{3}^{+}$for $\mathrm{OM}: \mathrm{rBC}>3, \sim 63 \%$ for the change in the last two data points for $d_{\mathrm{mob}}=220$ in Fig. 9a. Furthermore, with the increased fraction of particles being vaporized by the IR laser, it has been shown that fragmentation would decrease, thereby decreasing the contribution of SOA to $\mathrm{C}_{3}^{+}$ (Canagaratna et al., 2015b). Alternative explanations may include instrument differences and variability in IR laser beam width. This illustrates that particle-beam width is an important metric for quantitative measurements of BBA, even with a high SOA : $\mathrm{rBC}$ mass ratio $>9$ and particle vacuum aerodynamic diameters greater than $400 \mathrm{~nm}$.

\subsection{LAAPTOF quantification of OM on externally mixed soot particles}

Single-particle analysis provides valuable insight into the physical and chemical evolution of biomass-burning plumes as they are diluted by entrainment of background air and undergo transformation processes during transport. Singleparticle analysis also facilitates the determination of contributions from biomass-burning particles to aerosol loading for source apportionment and can reveal changes in the mixing state of biomass-burning particles as they age (Chen et al., 2014; Moffet et al., 2008; Silva et al., 1999; Zauscher et al., 2013). Although LDI, such as that used by the LAAPTOF, is often regarded as a semi-quantitative method, there are numerous examples demonstrating that it can be mass quantitative for constrained systems where similar particle matrices are studied (Healy et al., 2013; Jeong et al., 2011; Mansoori et al., 1994; Spencer and Prather, 2006; Sullivan et al., 2007, 2009). Quantitative mass measurements using (LDI-SP-MS) are difficult because of the particle matrix effects that influence how much energy is absorbed by a given particle and subsequently the production and fate of the generated ions (Murphy, 2007; Steele et al., 2005; Sullivan and Prather, 2005). Calibration of the LDI-SP-MS ion-signal response to particles of known composition is also required to yield mass-quantitative component measurements. The SOA-coated soot experiments we present here provide a unique opportunity to characterize the response of the LAAPTOF to realistic biomass-burning cores coated with complex and realistic biogenic SOA, where the masses of $\mathrm{rBC}$ and $\mathrm{OM}$ are well constrained.

We show the average OM signal per particle measured by the LAAPTOF in Fig. 12. We observed a large degree of molecular fragmentation; most of the OM signal appeared at $m / z+28$, which we attribute to $\mathrm{CO}^{+}$. All data points represent the average of at least five particles with a minimum of $100 \mathrm{~Hz}$ of total EC ion signal at $m / z+24,+36$, +48 , and +60 , representing $\mathrm{C}_{2-5}^{+}$. This excludes any homogeneously nucleated SOA particles and low-signal particles from the analysis. Of the 454 total particles detected, 160 particles met the above criteria. A linear regression fit of all LAAPTOF OM ion signal as a function of SOA mass per particle results in a $R^{2}=0.72(\mathrm{OM}$ signal $(\mathrm{Hz})=75(\mathrm{fg}$ SOA) + 167). This may be due to different light absorption and laser energy distribution properties of different sized soot cores. Narrowing the analysis to the experiment with $187 \mathrm{~nm}$ soot cores results in a highly linear fit with a $R^{2}=0.998$ $(\mathrm{OM}$ signal $(\mathrm{Hz})=120(\mathrm{fg} \mathrm{SOA})+179)$. SOA from a single precursor can still contain hundreds or thousands of organic compounds, with a broad range of molecular weights, degrees of functionalization, and optical properties (Zhang et al., 2015). Despite the complex nature of the SOA coating and BBA core, we observed a strong linear relationship between the amount of SOA condensed on the particle and the OM signal from the LAAPTOF. It is important to note that 


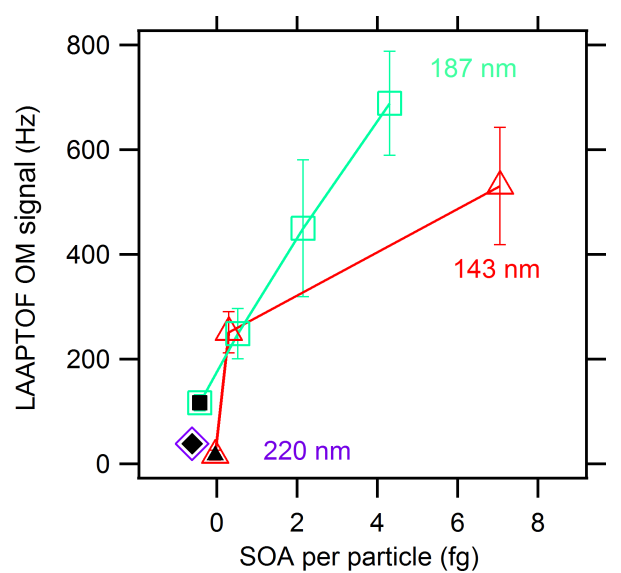

Figure 12. Averaged $\mathrm{OM}$ signal $\left(\mathrm{m} / z+28 ; \mathrm{CO}^{+}\right)$from nascent and SOA-coated soot particles measured by the LAAPTOF during SOA coating experiments vs. SOA mass per particle. Error bars indicate the standard error. There is a strong positive correlation despite the complex biomass-burning aerosol matrix. Open marker colors/shapes indicate the initial $d_{\mathrm{mob}}$ of the size-selected soot core, and black markers indicate nascent, uncoated soot particles.

although other LDI-SP-MS studies have found a good correlation between OM signal and reference measurements, this work shows that an even better correlation can be obtained if the analysis can be informed by the chemical information provided by the mass spectra. In this case we show that, with some improvements in excimer laser homogeneity, it may be possible for an algorithm to isolate $\mathrm{rBC}$-containing particles and identify the necessary function to convert $\mathrm{OM}$ signal into SOA mass per particle.

Figure 13 shows the same OM ion signal measured by the LAAPTOF plotted in Fig. 12, now normalized by the concurrent LAAPTOF EC ion signal. This parallels the analysis by ATOFMS of spark-generated EC particles coated by the condensation of diesel fuel presented by Spencer and Prather (2006), but using more complex and realistic particle EC and OM components. EC fragments used included $\mathrm{C}_{2-5}^{+}$but excluded $\mathrm{C}_{1}^{+}$because we have observed that $\mathrm{OM}$ can also be charred to $\mathrm{C}_{1}^{+}$and thus produce an interference to the quantification of $\mathrm{EC}$ at $m / z+12$. The $\mathrm{OM}: \mathrm{EC}$ ion ratio used here is thus $\mathrm{CO}^{+}: \mathrm{C}_{2-5}^{+}$. We use the ratio of OM / EC ions to account for laser shot-to-shot variability, where more ions may be generated due to increased laser fluence or increased absorption of laser energy. We sampled biomassburning particles that contained potassium salts, which ionize readily, as well as strongly light-absorbing $\mathrm{rBC}$ (Gross et al., 2000). This represents the complex composition of realistic aged BBA. Initial particles were composed mostly of black carbon, with initially variable shapes, and with an unknown distribution of potassium salts per particle. Despite the variability in the soot core composition of individual particles, a positive correlation between the amount of SOA mass per particle and the LAAPTOF ion signal from oxidized organics

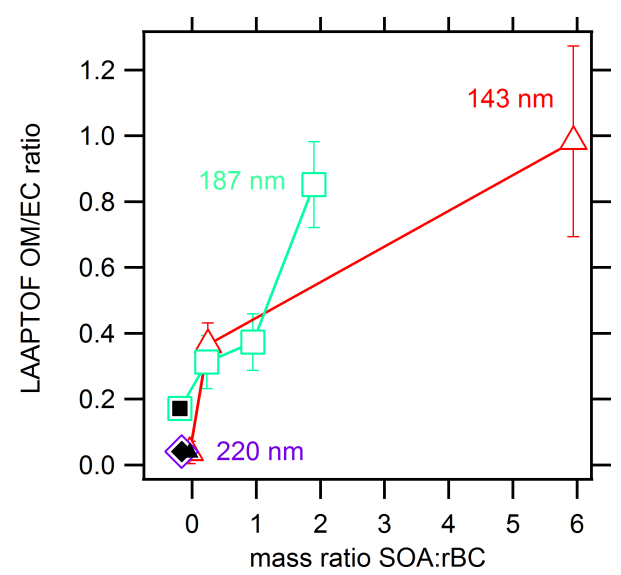

Figure 13. LAAPTOF-measured OM ion signal $\left(m / z+28 ; \mathrm{CO}^{+}\right)$ normalized by LAAPTOF EC ion signal (sum of $m / z+24,+36$, $+48,+60 ; \mathrm{C}_{2-5}^{+}$) for uncoated and SOA-coated soot particles. Error bars indicate the standard error. Here the OM : EC ratio is shown as a function of the ratio of mobility-derived SOA mass to SP2measured rBC. The LAAPTOF EC signal serves as an internal standard to normalize for the actual amount of laser energy the particle absorbed, which can change with increased rBC mass or SOA coating, and particle size and shape. Marker colors/shapes indicate the initial size-selected soot core $d_{\text {mob }}$ for each experiment.

was still observed from these mixed $\mathrm{rBC}$ and inorganic salt particles, when averaged over the many particles we sampled.

Other LDI-SP-MS instruments that use longer ionization wavelengths, such as $266 \mathrm{~nm}$ used in the ATOFMS, do not typically fragment oxidized organics to $\mathrm{CO}^{+}$; instead their major oxidized $\mathrm{OM}$ ion fragment is observed at $\mathrm{m} / \mathrm{z}+$ 43, presumably from $\mathrm{C}_{2} \mathrm{H}_{3} \mathrm{O}^{+}$(Moffet and Prather, 2009; Spencer and Prather, 2006). We operated the LAAPTOF's excimer laser at a moderate pulse energy of $2.0 \mathrm{~mJ}$, as a tradeoff between increased sensitivity while avoiding excessive decomposition or fragmentation of $\mathrm{OM}$ into $\mathrm{EC}_{n}^{+}$fragments. In the work described in Spencer and Prather (2006), graphitic soot particles with no condensed organics had an $\mathrm{OM}: \mathrm{EC}$ ion signal ratio of $\sim 0$, and those coated with a mass of condensed fuel equal to the EC mass had an OM: EC ion signal ratio of 2.25. For a similar OM : EC mass ratio $\sim 1$ in our experiments, we saw a more modest $\mathrm{OM}$ : EC ion ratio of $\sim 0.35$. This difference may be caused by differences in instrument operation and chemical composition of the refractory EC core and OM coating. The LAAPTOF uses an exciplex VUV laser at $193 \mathrm{~nm}$ (compared to the "softer" $266 \mathrm{~nm}$ Nd:YAG laser in the ATOFMS) and we observe more extensive molecular fragmentation of the OM. Thus, we quantified $\mathrm{OM}$ with a single ion $\left(\mathrm{CO}^{+}\right)$, compared to the various ions used by Spencer and Prather (i.e., $m / z+27,+29,+37$, $+43)$. A softer ionization might have resulted in less charring of SOA to $\mathrm{C}_{1}^{+}$in the LAAPTOF and thus increased the slope of the LAAPTOF-measured OM : EC ions versus mass frac- 
tion of SOA. Spencer and Prather used condensed diesel fuel vapors as their source of OM, while we used SOA from the ozonolysis of $\alpha$-pinene. Therefore, the OM used in the prior study was unoxidized primary organic aerosol, while our OM was highly oxidized complex secondary organic aerosol.

\section{Conclusions}

We investigated the response of two particle mass spectrometers to biomass-burning particles with carefully controlled amounts of organic matter and well characterized particle properties. Our analysis revealed a variety of particle morphologies and compositions, leading to a broad distribution of vacuum aerodynamic diameters at a single selected mobility diameter. As these particles of various compositions and shapes became coated with SOA, measurements using the beam-width probe of the SP-AMS revealed that the effective IR laser beam width for thermal ionization of potassium is larger than for vaporization of rBC. Future measurements using the SP-AMS would do well to quantify the particlebeam and effective IR laser beam overlap for the species of interest using beam width probe measurements. The fraction of $\mathrm{rBC}$-containing particles that experience sufficient laser fluence to vaporize the nonrefractory coating should always be greater than or equal to the fraction of particles whose refractory material is also vaporized. The use of optical components to change the IR laser from a Gaussian to a uniform flat-top energy profile would greatly simplify the analysis of rBC-containing soot particles by the SP-AMS by ensuring that all particles passing through the laser experience the same amount of energy. This would eliminate the difference given above regarding the fraction of $\mathrm{rBC}$-containing particles whose nonrefractory versus refractory components are detected.

Although these measurements explored thick SOA coatings and large particle sizes, we did not observe a plateau in instrument response to potassium or black carbon as the coating was increased. These findings have important implications for obtaining quantitative mass measurements and can help to better inform the analysis and interpretation of SP-AMS measurements of the emissions and aging of BBA (Corbin et al., 2015; Dallmann et al., 2014; Fortner et al., 2012; Lee et al., 2016; Massoli et al., 2015). We would like to add, however, that although changes in $d_{\mathrm{va}}$ may result in varying $E_{\mathrm{IR}}$, SP-AMS measurements of $\mathrm{rBC}$ have been shown to correlate with reference measurements (Fortner et al., 2012; Willis et al., 2014). This suggests that the changes in secondary aerosol mass required to cause large changes in $E_{\mathrm{IR}}$ for $\mathrm{rBC}$ did not happen on the timescale of those measurements.

Mass spectral analysis with the SP-AMS also revealed that increased SOA coatings on the biomass-burning soot changed the relative abundance of EC clusters. Specifically, as the particles became more thickly coated with SOA, the ratio of $\mathrm{C}_{>3}^{+}$to $\mathrm{C}_{3}^{+}$increased. The degree of change for the ratio of $\mathrm{C}_{4}^{+}$to $\mathrm{C}_{3}^{+}$was smaller than the precision suggested by Corbin et al. (2014) for identifying soot-particle source types using ratios of the elemental carbon ion family, $\mathrm{C}_{x}^{+}$. However, the observed ratio of $\mathrm{C}_{4}^{+}$to $\mathrm{C}_{3}^{+}$was inconsistent with that previously observed from quenched-combustion flame soot (Corbin et al., 2014; Maricq, 2014). This reinforces the need for thermal denuding of ambient soot samples before attempting source analysis using EC ratios.

Despite the challenges presented by complex particle composition and shape for laser desorption ionization singleparticle mass spectrometry, there is a strong correlation between the average $\mathrm{OM}$ ion signal measured by the LAAPTOF and the SOA mass per particle. Although this quantitative relationship has been shown previously for LDISP-MS analysis of graphite spark discharge soot coated by diesel fuel condensation (Spencer and Prather, 2006), this is the first time it has been explored with realistic combustion soot in the presence of inorganic components and complex realistic SOA. This opens the way for more quantitative single-particle measurements using techniques such as laserbeam homogenization and particle type informed ion sensitivity calibrations. Additional work is required to investigate the response of single-particle mass spectrometry to other atmospherically relevant core-shell combinations.

\section{Data availability}

Data are available upon request from R. Sullivan (rsullivan@cmu.edu).

Acknowledgements. A. T. Ahern and G. Saliba were partially supported by the Steinbrenner Graduate Research Fellowship. R. Subramanian was funded by the US Department of Energy Atmospheric Systems Research program through grant DESC0010121. The authors thank Claudio Mazzoleni for the loan of the CPMA. This work was supported in part by the National Science Foundation (awards CHE-1412309 and AGS-1552608). The views, opinions, and/or findings contained in this paper are those of the authors and should not be construed as an official position of the funding agencies.

Edited by: P. Herckes

Reviewed by: J. C. Corbin and one anonymous referee

\section{References}

Aiken, A. C., de Foy, B., Wiedinmyer, C., DeCarlo, P. F., Ulbrich, I. M., Wehrli, M. N., Szidat, S., Prevot, A. S. H., Noda, J., Wacker, L., Volkamer, R., Fortner, E., Wang, J., Laskin, A., Shutthanandan, V., Zheng, J., Zhang, R., Paredes-Miranda, G., Arnott, W. P., Molina, L. T., Sosa, G., Querol, X., and Jimenez, J. L.: Mexico city aerosol analysis during MILAGRO using high resolution aerosol mass spectrometry at the urban supersite (T0) - 
Part 2: Analysis of the biomass burning contribution and the non-fossil carbon fraction, Atmos. Chem. Phys., 10, 5315-5341, doi:10.5194/acp-10-5315-2010, 2010.

Alfarra, M.R.: Insights Into Atmospheric Organic Aerosols Using an Aerosol Mass Spectrometer, $\mathrm{PhD}$ Thesis, University of Manchester, 2004.

Allan, J. D., Delia, A. E., Coe, H., Bower, K. N., Rami Alfarra, M., Jimenez, J. L., Middlebrook, A. M., Drewnick, F., Onasch, T. B., Canagaratna, M. R., Jayne, J. T., Worsnop, D. R., and Allan, J. D.: A generalised method for the extraction of chemically resolved mass spectra from Aerodyne aerosol mass spectrometer data, Aerosol Sci., 35, 909-922, doi:10.1016/j.jaerosci.2004.02.007, 2004.

Andreae, M. O.: Soot carbon and excess fine potassium: long-range transport of combustion-derived aerosols, Science, 220, 11481151, doi:10.1126/science.220.4602.1148, 1983.

Anenberg, S. C., Schwartz, J., Shindell, D., Amann, M., Faluvegi, G., Klimont, Z., Janssens-Maenhout, G., Pozzoli, L., Van Dingenen, R., Vignati, E., Emberson, L., Muller, N. Z., West, J. J., Williams, M., Demkine, V., Hicks, W. K., Kuylenstierna, J., Raes, F., and Ramanathan, V.: Global Air Quality and Health Co-benefits of Mitigating Near-Term Climate Change through Methane and Black Carbon Emission Controls, Environ. Health Perspect., 120, 831-839, doi:10.1289/ehp.1104301, 2012.

Bahadur, R., Russell, L. M., and Prather, K. A.: Composition and Morphology of Individual Combustion, Biomass Burning, and Secondary Organic Particle Types Obtained Using Urban and Coastal ATOFMS and STXM-NEXAFS Measurements, Aerosol Sci. Technol., 44, 551-562, doi:10.1080/02786821003786048, 2010.

Bhave, P. V, Allen, J. O., Morrical, B. D., Fergenson, D. P., Cass, G. R., and Prather, K. A.: A Field-Based Approach for Determining ATOFMS Instrument Sensitivities to Ammonium and Nitrate, Environ. Sci. Technol., 36, 4868-4879, doi:10.1021/es015823i, 2002.

Bloomfield, L. A., Geusic, M. E., Freeman, R. R., and Brown, W. L.: Negative and positive cluster ions of carbon and silicon, Chem. Phys. Lett., 121, 33-37, doi:10.1016/0009-2614(85)87149-9, 1985.

Bond, T. C., Habib, G., and Bergstrom, R. W.: Limitations in the enhancement of visible light absorption due to mixing state, J. Geophys. Res.-Atmos., 111, 1-13, doi:10.1029/2006JD007315, 2006.

Bond, T. C., Doherty, S. J., Fahey, D. W., Forster, P. M., Berntsen, T., DeAngelo, B. J., Flanner, M. G., Ghan, S., Kärcher, B., Koch, D., Kinne, S., Kondo, Y., Quinn, P. K., Sarofim, M. C., Schultz, M. G., Schulz, M., Venkataraman, C., Zhang, H., Zhang, S., Bellouin, N., Guttikunda, S. K., Hopke, P. K., Jacobson, M. Z., Kaiser, J. W., Klimont, Z., Lohmann, U., Schwarz, J. P., Shindell, D., Storelvmo, T., Warren, S. G., and Zender, C. S.: Bounding the role of black carbon in the climate system: A scientific assessment, J. Geophys. Res.-Atmos., 118, 5380-5552, doi:10.1002/jgrd.50171, 2013.

Branca, C., Iannace, A., and Di Blasi, C.: Devolatilization and Combustion Kinetics of Quercus cerris Bark, Energ. Fuel., 21, 10781084, doi:10.1021/ef060537j, 2007.

Canagaratna, M. R., Jimenez, J. L., Kroll, J. H., Chen, Q., Kessler, S. H., Massoli, P., Hildebrandt Ruiz, L., Fortner, E., Williams, L. R., Wilson, K. R., Surratt, J. D., Donahue, N. M., Jayne, J. T., and Worsnop, D. R.: Elemental ratio measurements of organic compounds using aerosol mass spectrometry: characterization, improved calibration, and implications, Atmos. Chem. Phys., 15, 253-272, doi:10.5194/acp-15-253-2015, 2015a.

Canagaratna, M. R., Massoli, P., Browne, E. C., Franklin, J. P., Wilson, K. R., Onasch, T. B., Kirchstetter, T. W., Fortner, E. C., Kolb, C. E., Jayne, J. T., Kroll, J. H., and Worsnop, D. R.: Chemical Compositions of Black Carbon Particle Cores and Coatings via Soot Particle Aerosol Mass Spectrometry with Photoionization and Electron Ionization, J. Phys. Chem. A, 119, 4589-4599, doi:10.1021/jp510711u, 2015b.

Carbone, S., Onasch, T., Saarikoski, S., Timonen, H., Saarnio, K., Sueper, D., Rönkkö, T., Pirjola, L., Häyrinen, A., Worsnop, D., and Hillamo, R.: Characterization of trace metals on soot aerosol particles with the SP-AMS: detection and quantification, Atmos. Meas. Tech., 8, 4803-4815, doi:10.5194/amt-8-4803-2015, 2015.

Chen, K., Yin, Y., Kong, S., Xiao, H., Wu, Y., Chen, J., and Li, A.: Size-resolved chemical composition of atmospheric particles during a straw burning period at Mt. Huang (the Yellow Mountain) of China, Atmos. Environ., 84, 380-389, doi:10.1016/j.atmosenv.2013.11.040, 2014.

Chhabra, P. S., Flagan, R. C., and Seinfeld, J. H.: Elemental analysis of chamber organic aerosol using an aerodyne high-resolution aerosol mass spectrometer, Atmos. Chem. Phys., 10, 4111-4131, doi:10.5194/acp-10-4111-2010, 2010.

Chung, S. H. and Seinfeld, J. H.: Global distribution and climate forcing of carbonaceous aerosols, J. Geophys. Res., 107, 4407, doi:10.1029/2001JD001397, 2002.

Corbin, J. C., Sierau, B., Gysel, M., Laborde, M., Keller, A., Kim, J., Petzold, A., Onasch, T. B., Lohmann, U., and Mensah, A. A.: Mass spectrometry of refractory black carbon particles from six sources: carbon-cluster and oxygenated ions, Atmos. Chem. Phys., 14, 2591-2603, doi:10.5194/acp-14-2591-2014, 2014.

Corbin, J. C., Lohmann, U., Sierau, B., Keller, A., Burtscher, H., and Mensah, A. A.: Black carbon surface oxidation and organic composition of beech-wood soot aerosols, Atmos. Chem. Phys., 15, 11885-11907, doi:10.5194/acp-15-11885-2015, 2015.

Cross, E. S., Onasch, T. B., Ahern, A., Wrobel, W., Slowik, J. G., Olfert, J., Lack, D. A., Massoli, P., Cappa, C. D., Schwarz, J. P., Spackman, J. R., Fahey, D. W., Sedlacek, A., Trimborn, A., Jayne, J. T., Freedman, A., Williams, L. R., Ng, N. L., Mazzoleni, C., Dubey, M., Brem, B., Kok, G., Subramanian, R., Freitag, S., Clarke, A., Thornhill, D., Marr, L. C., Kolb, C. E., Worsnop, D. R., and Davidovits, P.: Soot Particle Studies - Instrument InterComparison - Project Overview, Aerosol Sci. Technol., 44, 592611, doi:10.1080/02786826.2010.482113, 2010.

Cubison, M. J., Ortega, A. M., Hayes, P. L., Farmer, D. K., Day, D., Lechner, M. J., Brune, W. H., Apel, E., Diskin, G. S., Fisher, J. A., Fuelberg, H. E., Hecobian, A., Knapp, D. J., Mikoviny, T., Riemer, D., Sachse, G. W., Sessions, W., Weber, R. J., Weinheimer, A. J., Wisthaler, A., and Jimenez, J. L.: Effects of aging on organic aerosol from open biomass burning smoke in aircraft and laboratory studies, Atmos. Chem. Phys., 11, 12049-12064, doi:10.5194/acp-11-12049-2011, 2011.

Dallmann, T. R., Onasch, T. B., Kirchstetter, T. W., Worton, D. R., Fortner, E. C., Herndon, S. C., Wood, E. C., Franklin, J. P., Worsnop, D. R., Goldstein, A. H., and Harley, R. A.: Characterization of particulate matter emissions from on-road gasoline and 
diesel vehicles using a soot particle aerosol mass spectrometer, Atmos. Chem. Phys., 14, 7585-7599, doi:10.5194/acp-14-75852014, 2014.

DeCarlo, P. F., Slowik, J. G., Worsnop, D. R., Davidovits, P., and Jimenez, J. L.: Particle Morphology and Density Characterization by Combined Mobility and Aerodynamic Diameter Measurements. Part 1: Theory, Aerosol Sci. Technol., 38, 1185-1205, doi:10.1080/027868290903907, 2004.

DeCarlo, P. F., Kimmel, J. R., Trimborn, A., Northway, M. J., Jayne, J. T., Aiken, A. C., Gonin, M., Fuhrer, K., Horvath, T., Docherty, K. S., Worsnop, D. R., and Jimenez, J. L.: Field-depoloyable, high-resolution, time-offlight aerosol mass spectrometer, Anal. Chem., 78, 8281-8289, doi:8410.1029/2001JD001213. Analytical, 2006.

Drewnick, F., Hings, S. S., Curtius, J., Eerdekens, G., and Williams, J.: Measurement of fine particulate and gas-phase species during the New Year's fireworks 2005 in Mainz, Germany, Atmos. Environ., 40, 4316-4327, doi:10.1016/j.atmosenv.2006.03.040, 2006.

Farmer, D. K. and Jimenez, J. L.: Real-time Atmospheric Chemistry Field Instrumentation, Anal. Chem., 82, 7879-7884, doi:10.1021/ac1010603, 2010.

Farmer, D. K., Matsunaga, A., Docherty, K. S., Surratt, J. D., Seinfeld, J. H., Ziemann, P. J., and Jimenez, J. L.: Response of an aerosol mass spectrometer to organonitrates and organosulfates and implications for atmospheric chemistry, P. Natl. Acad. Sci. USA, 107, 6670-6675, doi:10.1073/pnas.0912340107, 2010.

Fergenson, D. P., Song, X.-H., Ramadan, Z., Allen, J. O., Hughes, L. S., Cass, G. R., Hopke, P. K., and Prather, K. A.: Quantification of ATOFMS Data by Multivariate Methods, Anal. Chem., 73, 3535-3541, doi:10.1021/ac010022j, 2001.

Fortner, E. C., Brooks, W. A., Onasch, T. B., Canagaratna, M. R., Massoli, P., Jayne, J. T., Franklin, J. P., Knighton, W. B., Wormhoudt, J., Worsnop, D. R., Kolb, C. E., and Herndon, S. C.: Particulate Emissions Measured During the TCEQ Comprehensive Flare Emission Study, Ind. Eng. Chem. Res., 51, 1258612592, doi:10.1021/ie202692y, 2012.

Gemayel, R., Hellebust, S., Temime-Roussel, B., Hayeck, N., Van Elteren, J. T., Wortham, H., and Gligorovski, S.: The performance and the characterization of laser ablation aerosol particle time-of-flight mass spectrometry (LAAP-ToF-MS), Atmos. Meas. Tech., 9, 1947-1959, doi:10.5194/amt-9-1947-2016, 2016.

Ghazi, R. and Olfert, J. S.: Coating Mass Dependence of Soot Aggregate Restructuring due to Coatings of Oleic Acid and Dioctyl Sebacate, Aerosol Sci. Technol., 47, 192-200, doi:10.1080/02786826.2012.741273, 2013.

Gross, D. S., Gälli, M. E., Silva, P. J., and Prather, K. A.: Relative Sensitivity Factors for Alkali Metal and Ammonium Cations in Single-Particle Aerosol Time-of-Flight Mass Spectra, Anal. Chem., 72, 416-422, doi:10.1021/ac990434g, 2000.

Gysel, M., Laborde, M., Olfert, J. S., Subramanian, R., and Gröhn, A. J.: Effective density of Aquadag and fullerene soot black carbon reference materials used for SP2 calibration, Atmos. Meas. Tech., 4, 2851-2858, doi:10.5194/amt-4-2851-2011, 2011.

Gysel, M., Laborde, M., Mensah, A. A., Corbin, J. C., Keller, A., Kim, J., Petzold, A., and Sierau, B.: Technical Note: The single particle soot photometer fails to reliably detect PALAS soot nanoparticles, Atmos. Meas. Tech., 5, 3099-3107, doi:10.5194/amt-5-3099-2012, 2012.
Healy, R. M., Sciare, J., Poulain, L., Kamili, K., Merkel, M., Müller, T., Wiedensohler, A., Eckhardt, S., Stohl, A., Sarda-Estève, R., McGillicuddy, E., O'Connor, I. P., Sodeau, J. R., and Wenger, J. C.: Sources and mixing state of size-resolved elemental carbon particles in a European megacity: Paris, Atmos. Chem. Phys., 12, 1681-1700, doi:10.5194/acp-12-1681-2012, 2012.

Healy, R. M., Sciare, J., Poulain, L., Crippa, M., Wiedensohler, A., Prévôt, A. S. H., Baltensperger, U., Sarda-Estève, R., McGuire, M. L., Jeong, C.-H., McGillicuddy, E., O'Connor, I. P., Sodeau, J. R., Evans, G. J., and Wenger, J. C.: Quantitative determination of carbonaceous particle mixing state in Paris using single-particle mass spectrometer and aerosol mass spectrometer measurements, Atmos. Chem. Phys., 13, 9479-9496, doi:10.5194/acp13-9479-2013, 2013.

Hennigan, C. J., Sullivan, A. P., Collett, J. L., and Robinson, A. L.: Levoglucosan stability in biomass burning particles exposed to hydroxyl radicals, Geophys. Res. Lett., 37, 2-5, doi:10.1029/2010GL043088, 2010.

Hennigan, C. J., Miracolo, M. A., Engelhart, G. J., May, A. A., Presto, A. A., Lee, T., Sullivan, A. P., McMeeking, G. R., Coe, H., Wold, C. E., Hao, W.-M., Gilman, J. B., Kuster, W. C., de Gouw, J., Schichtel, B. A., Collett Jr., J. L., Kreidenweis, S. M., and Robinson, A. L.: Chemical and physical transformations of organic aerosol from the photo-oxidation of open biomass burning emissions in an environmental chamber, Atmos. Chem. Phys., 11, 7669-7686, doi:10.5194/acp-11-7669-2011, 2011.

Huffman, J. A., Jayne, J. T., Drewnick, F., Aiken, A. C., Onasch, T., Worsnop, D. R., and Jimenez, J. L.: Design, Modeling, Optimization, and Experimental Tests of a Particle Beam Width Probe for the Aerodyne Aerosol Mass Spectrometer, Aerosol Sci. Technol., 39, 1143-1163, doi:10.1080/02786820500423782, 2005.

Jacobson, M. Z.: Strong radiative heating due to the mixing state of black carbon in atmospheric aerosols, Nature, 409, 695-697, doi:10.1038/35055518, 2001.

Jayne, J. T., Leard, D. C., Zhang, X., Davidovits, P., Smith, K. A., Kolb, C. E., and Worsnop, D. R.: Development of an Aerosol Mass Spectrometer for Size and Composition Analysis of Submicron Particles, Aerosol Sci. Technol., 33, 49-70, doi:10.1080/027868200410840, 2000.

Jeong, C.-H., McGuire, M. L., Godri, K. J., Slowik, J. G., Rehbein, P. J. G., and Evans, G. J.: Quantification of aerosol chemical composition using continuous single particle measurements, Atmos. Chem. Phys., 11, 7027-7044, doi:10.5194/acp-11-70272011, 2011.

Kroll, J. H., Donahue, N. M., Jimenez, J. L., Kessler, S. H., Canagaratna, M. R., Wilson, K. R., Altieri, K. E., Mazzoleni, L. R., Wozniak, A. S., Bluhm, H., Mysak, E. R., Smith, J. D., Kolb, C. E., and Worsnop, D. R.: Carbon oxidation state as a metric for describing the chemistry of atmospheric organic aerosol, Nat. Chem., 3, 133-139, doi:10.1038/nchem.948, 2011.

Lack, D. A., Cappa, C. D., Cross, E. S., Massoli, P., Ahern, A. T., Davidovits, P., and Onasch, T. B.: Absorption Enhancement of Coated Absorbing Aerosols: Validation of the Photo-Acoustic Technique for Measuring the Enhancement, Aerosol Sci. Technol., 43, 1006-1012, doi:10.1080/02786820903117932, 2009.

Lee, A. K. Y., Willis, M. D., Healy, R. M., Wang, J. M., Jeong, C.-H., Wenger, J. C., Evans, G. J., and Abbatt, J. P. D.: Singleparticle characterization of biomass burning organic aerosol (BBOA): evidence for non-uniform mixing of high molecular 
weight organics and potassium, Atmos. Chem. Phys., 16, 55615572, doi:10.5194/acp-16-5561-2016, 2016.

Lee, T., Sullivan, A. P., Mack, L., Jimenez, J. L., Kreidenweis, S. M., Onasch, T. B., Worsnop, D. R., Malm, W., Wold, C. E., Hao, W. M., and Collett, J. L.: Chemical Smoke Marker Emissions During Flaming and Smoldering Phases of Laboratory Open Burning of Wildland Fuels, Aerosol Sci. Technol., 44, i-v, doi:10.1080/02786826.2010.499884, 2010.

Levin, E. J. T., McMeeking, G. R., Carrico, C. M., Mack, L. E., Kreidenweis, S. M., Wold, C. E., Moosmüller, H., Arnott, W. P., Hao, W. M., Collett, J. L., and Malm, W. C.: Biomass burning smoke aerosol properties measured during Fire Laboratory at Missoula Experiments (FLAME), J. Geophys. Res., 115, 1-15, doi:10.1029/2009JD013601, 2010.

Li, J., Posfai, M., Hobbs, P. V., and Buseck, P. R.: Individual Aerosol Particles from Biomass Burning in Southern Africa Compositions and Aging of Inorganic Particles, J. Geophys. Res.-Atmos., 108, 1-12, doi:10.1029/2002JD002310, 2003.

Liu, P., Ziemann, P. J., Kittelson, D. B., and McMurry, P. H.: Generating Particle Beams of Controlled Dimensions and Divergence: II. Experimental Evaluation of Particle Motion in Aerodynamic Lenses and Nozzle Expansions, Aerosol Sci. Technol., 22, 314 324, doi:10.1080/02786829408959749, 1995.

Liu, P. S. K., Deng, R., Smith, K. A., Williams, L. R., Jayne, J. T., Canagaratna, M. R., Moore, K., Onasch, T. B., Worsnop, D. R., and Deshler, T.: Transmission Efficiency of an Aerodynamic Focusing Lens System: Comparison of Model Calculations and Laboratory Measurements for the Aerodyne Aerosol Mass Spectrometer, Aerosol Sci. Technol., 41, 721-733, doi:10.1080/02786820701422278, 2007.

Mansoori, B. A., Johnston, M. V., and Wexler, A. S.: Quantitation of Ionic Species in Single Microdroplets by Online Laser Desorption/Ionization, Anal. Chem., 66, 3681-3687, doi:10.1021/ac00093a023, 1994.

Mansoori, B. A., Johnston, M. V., and Wexler, A. S.: MatrixAssisted Laser Desorption/Ionization of Size- and CompositionSelected Aerosol Particles, Anal. Chem., 68, 3595-3601, doi:10.1021/ac9603385, 1996.

Maricq, M. M.: Examining the Relationship Between Black Carbon and Soot in Flames and Engine Exhaust, Aerosol Sci. Technol., 48, 620-629, doi:10.1080/02786826.2014.904961, 2014.

Marsden, N., Flynn, M. J., Taylor, J. W., Allan, J. D., and Coe, H.: Evaluating the influence of laser wavelength and detection stage geometry on optical detection efficiency in a singleparticle mass spectrometer, Atmos. Meas. Tech., 9, 6051-6068, doi:10.5194/amt-9-6051-2016, 2016.

Massoli, P., Onasch, T. B., Cappa, C. D., Nuamaan, I., Hakala, J., Hayden, K., Li, S.-M., Sueper, D. T., Bates, T. S., Quinn, P. K., Jayne, J. T., and Worsnop, D. R.: Characterization of black carbon-containing particles from soot particle aerosol mass spectrometer measurements on the R/V Atlantis during CalNex 2010, J. Geophys. Res.-Atmos., 120, 2575-2593, doi:10.1002/2014JD022834, 2015.

May, A. A., Levin, E. J. T., Hennigan, C. J., Riipinen, I., Lee, T., Collett, J. L., Jimenez, J. L., Kreidenweis, S. M., and Robinson, A. L.: Gas-particle partitioning of primary organic aerosol emissions: 3. Biomass burning, J. Geophys. Res.-Atmos., 118, 11327-11338, doi:10.1002/jgrd.50828, 2013.
Mikhailov, E. F., Vlasenko, S. S., Podgorny, I. A., Ramanathan, V., and Corrigan, C. E.: Optical properties of soot-water drop agglomerates: An experimental study, J. Geophys. Res., 111, D07209, doi:10.1029/2005JD006389, 2006.

Moffet, R. C. and Prather, K. A.: In-situ measurements of the mixing state and optical properties of soot with implications for radiative forcing estimates, P. Natl. Acad. Sci. USA, 106, 11872 11877, doi:10.1073/pnas.0900040106, 2009.

Moffet, R. C., de Foy, B., Molina, L. T., Molina, M. J., and Prather, K. A.: Measurement of ambient aerosols in northern Mexico City by single particle mass spectrometry, Atmos. Chem. Phys., 8, 4499-4516, doi:10.5194/acp-8-4499-2008, 2008.

Moteki, N. and Kondo, Y.: Effects of Mixing State on Black Carbon Measurements by Laser-Induced Incandescence, Aerosol Sci. Technol., 41, 398-417, doi:10.1080/02786820701199728, 2007.

Murphy, D.: The design of single particle laser mass spectrometers, Mass Spectrom. Rev., 26, 150-165, doi:10.1002/mas.20113, 2007.

Murray, K. K. and Russell, D. H.: Aerosol matrix-assisted laser desorption ionization mass spectrometry, J. Am. Soc. Mass Spectrom., 5, 1-9, doi:10.1016/1044-0305(94)85077-1, 1994.

Neubauer, K. R., Johnston, M. V., and Wexler, A. S.: Humidity effects on the mass spectra of single aerosol particles, Atmos. Environ., 32, 2521-2529, doi:10.1016/S1352-2310(98)00005-3, 1998.

Onasch, T. B., Trimborn, A., Fortner, E. C., Jayne, J. T., Kok, G. L., Williams, L. R., Davidovits, P., and Worsnop, D. R.: Soot Particle Aerosol Mass Spectrometer: Development, Validation, and Initial Application, Aerosol Sci. Technol., 46, 804-817, doi:10.1080/02786826.2012.663948, 2012.

Onasch, T. B., Fortner, E. C., Trimborn, A. M., Lambe, A. T., Tiwari, A. J., Marr, L. C., Corbin, J. C., Mensah, A. A., Williams, L. R., Davidovits, P., and Worsnop, D. R.: Investigations of SP-AMS Carbon Ion Distributions as a Function of Refractory Black Carbon Particle Type, Aerosol Sci. Technol., 49, 409-422, doi:10.1080/02786826.2015.1039959, 2015.

Park, K., Kittelson, D. B., Zachariah, M. R., and McMurry, P. H.: Measurement of Inherent Material Density of Nanoparticle Agglomerates, J. Nanoparticle Res., 6, 267-272, doi:10.1023/B:NANO.0000034657.71309.e6, 2004.

Pósfai, M. and Buseck, P. R.: Nature and Climate Effects of Individual Tropospheric Aerosol Particles, Annu. Rev. Earth Pl. Sc., 38, 17-43, doi:10.1146/annurev.earth.031208.100032, 2010.

Pratt, K. A. and Prather, K. A.: Mass spectrometry of atmospheric aerosols-Recent developments and applications. Part II: On-line mass spectrometry techniques, Mass Spectrom. Rev., 31, 17-48, doi:10.1002/mas.20330, 2012.

Pratt, K., Mayer, J., and Holecek, J.: Development and characterization of an aircraft aerosol time-of-flight mass spectrometer, Anal. Chem., 81, 1792-1800, doi:10.1021/ac801942r, 2009.

Ramanathan, V. and Carmichael, G.: Global and regional climate changes due to black carbon, Nat. Geosci., 1, 221-227, doi:10.1038/ngeo156, 2008.

Reid, J. S. and Hobbs, P. V.: Physical and optical properties of young smoke from individual biomass fires in Brazil, J. Geophys. Res.Atmos., 103, 32013-32030, doi:10.1029/98JD00159, 1998.

Reid, J. S., Koppmann, R., Eck, T. F., and Eleuterio, D. P.: A review of biomass burning emissions part II: intensive physical proper- 
ties of biomass burning particles, Atmos. Chem. Phys., 5, 799825, doi:10.5194/acp-5-799-2005, 2005.

Reinard, M. S. and Johnston, M. V: Ion formation mechanism in laser desorption ionization of individual nanoparticles, J. Am. Soc. Mass Spectrom., 19, 389-399, doi:10.1016/j.jasms.2007.11.017, 2008.

Saliba, G., Subramanian, R., Saleh, R., Ahern, A. T., Lipsky, E. M., Tasoglou, A., Sullivan, R. C., Bhandari, J., Mazzoleni, C. and Robinson, A. L.: Optical properties of black carbon in cookstove emissions coated with secondary organic aerosols: Measurements and modeling, Aerosol Sci. Technol., 50, 1264-1276, doi:10.1080/02786826.2016.1225947, 2016.

Schwarz, J. P., Gao, R. S., Spackman, J. R., Watts, L. A., Thomson, D. S., Fahey, D. W., Ryerson, T. B., Peischl, J., Holloway, J. S., Trainer, M., Frost, G. J., Baynard, T., Lack, D. A., de Gouw, J. A., Warneke, C., and Del Negro, L. A.: Measurement of the mixing state, mass, and optical size of individual black carbon particles in urban and biomass burning emissions, Geophys. Res. Lett., 35, L13810, doi:10.1029/2008GL033968, 2008.

Schwarz, J. P., Spackman, J. R., Gao, R. S., Perring, A. E., Cross, E., Onasch, T. B., Ahern, A., Wrobel, W., Davidovits, P., Olfert, J., Dubey, M. K., Mazzoleni, C., and Fahey, D. W.: The Detection Efficiency of the Single Particle Soot Photometer, Aerosol Sci. Technol., 44, 612-628, doi:10.1080/02786826.2010.481298, 2010.

Shilling, J. E., Chen, Q., King, S. M., Rosenoern, T., Kroll, J. H., Worsnop, D. R., McKinney, K. A., and Martin, S. T.: Particle mass yield in secondary organic aerosol formed by the dark ozonolysis of $\alpha$-pinene, Atmos. Chem. Phys., 8, 2073-2088, doi:10.5194/acp-8-2073-2008, 2008.

Silva, P. J., Liu, D.-Y., Noble, C. A., and Prather, K. A.: Size and Chemical Characterization of Individual Particles Resulting from Biomass Burning of Local Southern California Species, Environ. Sci. Technol., 33, 3068-3076, doi:10.1021/es980544p, 1999.

Slowik, J., Stainken, K., Davidovits, P., Williams, L. R., Jayne, J. T., Kolb, C. E., Worsnop, D., Rudich, Y., DeCarlo, P., and Jimenez, J.: Particle Morphology and Density Characterization by Combined Mobility and Aerodynamic Diameter Measurements. Part 2: Application to Combustion-Generated Soot Aerosols as a Function of Fuel Equivalence Ratio, Aerosol Sci. Technol., 38, 1206-1222, doi:10.1080/02786826.2004.10399462, 2004.

Slowik, J. G., Cross, E. S., Han, J.-H., Davidovits, P., Onasch, T. B., Jayne, J. T., Williams, L. R., Canagaratna, M. R., Worsnop, D. R., Chakrabarty, R. K., Moosmüller, H., Arnott, W. P., Schwarz, J. P., Gao, R.-S., Fahey, D. W., Kok, G. L., and Petzold, A.: An Inter-Comparison of Instruments Measuring Black Carbon Content of Soot Particles, Aerosol Sci. Technol., 41, 295-314, doi:10.1080/02786820701197078, 2007.

Spencer, M. T. and Prather, K. A.: Using ATOFMS to Determine OC/EC Mass Fractions in Particles, Aerosol Sci. Technol., 40, 585-594, doi:10.1080/02786820600729138, 2006.

Steele, P. T., Srivastava, A., Pitesky, M. E., Fergenson, D. P., Tobias, H. J., Gard, E. E., and Frank, M.: Desorption/ionization fluence thresholds and improved mass spectral consistency measured using a flattop laser profile in the bioaerosol mass spectrometry of single Bacillus endospores, Anal. Chem., 77, 74487454, doi:10.1021/ac051329b, 2005.
Stephens, M., Turner, N., and Sandberg, J.: Particle identification by laser-induced incandescence in a solid-state laser cavity, Appl. Opt., 42, 3726-3736, doi:10.1364/AO.42.003726, 2003.

Stockwell, C. E., Veres, P. R., Williams, J., and Yokelson, R. J.: Characterization of biomass burning emissions from cooking fires, peat, crop residue, and other fuels with high-resolution proton-transfer-reaction time-of-flight mass spectrometry, Atmos. Chem. Phys., 15, 845-865, doi:10.5194/acp-15-845-2015, 2015.

Sullivan, R. C. and Prather, K. A.: Recent Advances in Our Understanding of Atmospheric Chemistry and Climate Made Possible by On-Line Aerosol Analysis Instrumentation, Anal. Chem., 77, 3861-3886, doi:10.1021/ac050716i, 2005.

Sullivan, R. C., Guazzotti, S. A., Sodeman, D. A., and Prather, K. A.: Direct observations of the atmospheric processing of Asian mineral dust, Atmos. Chem. Phys., 7, 1213-1236, doi:10.5194/acp-7-1213-2007, 2007.

Sullivan, R. C., Moore, M. J. K., Petters, M. D., Kreidenweis, S. M., Roberts, G. C., and Prather, K. A.: Timescale for hygroscopic conversion of calcite mineral particles through heterogeneous reaction with nitric acid, Phys. Chem. Chem. Phys., 11, 7826, doi:10.1039/b904217b, 2009.

Svane, M., Hagström, M., and Pettersson, J.: Chemical Analysis of Individual Alkali-Containing Aerosol Particles: Design and Performance of a Surface Ionization Particle Beam Mass Spectrometer, Aerosol Sci. Technol., 38, 655-663, doi:10.1080/02786820490485944, 2004.

Thomson, D. S., Middlebrook, A. M., and Murphy, D. M.: Thresholds for Laser-Induced Ion Formation from Aerosols in a Vacuum Using Ultraviolet and Vacuum-Ultraviolet Laser Wavelengths, Aerosol Sci. Technol., 26, 544-559, doi:10.1080/02786829708965452, 1997.

Thomson, D. S., Schein, M. E., and Murphy, D. M.: Particle Analysis by Laser Mass Spectrometry WB-57F Instrument Overview, Aerosol Sci. Technol., 33, 153-169, doi:10.1080/027868200410903, 2000.

Vander Wal, R. L. and Choi, M. Y.: Pulsed laser heating of soot: morphological changes, Carbon N. Y., 37, 231-239, doi:10.1016/S0008-6223(98)00169-9, 1999.

Vander Wal, R. L. and Jensen, K. A.: Laser-induced incandescence: excitation intensity, Appl. Opt., 37, 1607, doi:10.1364/AO.37.001607, 1998.

Vander Wal, R. L. and Tomasek, A. J.: Soot nanostructure: dependence upon synthesis conditions, Combust. Flame, 136, 129140, doi:10.1016/j.combustflame.2003.09.008, 2004.

Wenzel, R. J. and Prather, K. A.: Improvements in ion signal reproducibility obtained using a homogeneous laser beam for on-line laser desorption/ionization of single particles, Rapid Commun. Mass Sp., 18, 1525-1533, doi:10.1002/rcm.1509, 2004.

Willis, M. D., Lee, A. K. Y., Onasch, T. B., Fortner, E. C., Williams, L. R., Lambe, A. T., Worsnop, D. R., and Abbatt, J. P. D.: Collection efficiency of the soot-particle aerosol mass spectrometer (SP-AMS) for internally mixed particulate black carbon, Atmos. Meas. Tech., 7, 4507-4516, doi:10.5194/amt-7-4507-2014, 2014.

Yokelson, R. J., Crounse, J. D., DeCarlo, P. F., Karl, T., Urbanski, S., Atlas, E., Campos, T., Shinozuka, Y., Kapustin, V., Clarke, A. D., Weinheimer, A., Knapp, D. J., Montzka, D. D., Holloway, J., Weibring, P., Flocke, F., Zheng, W., Toohey, D., Wennberg, P. 
O., Wiedinmyer, C., Mauldin, L., Fried, A., Richter, D., Walega, J., Jimenez, J. L., Adachi, K., Buseck, P. R., Hall, S. R., and Shetter, R.: Emissions from biomass burning in the Yucatan, Atmos. Chem. Phys., 9, 5785-5812, doi:10.5194/acp-9-5785-2009, 2009.

Zandberg, E. Y.: Surface Ionization Detection of Particles, Tech. Phys., 40, 865-884, 1995.

Zandberg, E. Y. and Ionov, N. I.: Surface Ionization (translated from Russian), Israel program for scientific translations, Israel Program for Scientific Translations, Jerusalem, 355 pp., 1971

Zauscher, M. D., Wang, Y., Moore, M. J. K., Gaston, C. J., and Prather, K. A.: Air quality impact and physicochemical aging of biomass burning aerosols during the 2007 San Diego wildfires, Environ. Sci. Technol., 47, 7633-7643, doi:10.1021/es4004137, 2013.

Zelenyuk, A., Yang, J., Song, C., Zaveri, R. A., and Imre, D.: A New Real-Time Method for Determining Particles' Sphericity and Density: Application to Secondary Organic Aerosol Formed by Ozonolysis of $\alpha$-Pinene, Environ. Sci. Technol., 42, 80338038, doi:10.1021/es8013562, 2008.
Zelenyuk, A., Yang, J., Choi, E., and Imre, D.: SPLAT II: An Aircraft Compatible, Ultra-Sensitive, High Precision Instrument for In-Situ Characterization of the Size and Composition of Fine and Ultrafine Particles, Aerosol Sci. Technol., 43, 411-424, doi:10.1080/02786820802709243, 2009.

Zhang, J., Huff Hartz, K. E., Pandis, S. N., and Donahue, N. M.: Secondary Organic Aerosol Formation from Limonene Ozonolysis: Homogeneous and Heterogeneous Influences as a Function of $\mathrm{NO}_{x}$, J. Phys. Chem. A, 110, 11053-11063, doi:10.1021/jp062836f, 2006.

Zhang, R., Khalizov, A. F., Pagels, J., Zhang, D., Xue, H., and McMurry, P. H.: Variability in morphology, hygroscopicity, and optical properties of soot aerosols during atmospheric processing, P. Natl. Acad. Sci. USA, 105, 10291-10296, doi:10.1073/pnas.0804860105, 2008.

Zhang, X., McVay, R. C., Huang, D. D., Dalleska, N. F., Aumont, B., Flagan, R. C., and Seinfeld, J. H.: Formation and evolution of molecular products in $\alpha$-pinene secondary organic aerosol, P. Natl. Acad. Sci. USA, 112, 14168-14173, doi:10.1073/pnas.1517742112, 2015. 